\title{
Understanding Myopia: Pathogenesis and Mechanisms
}

\author{
Ranjay Chakraborty, Scott A. Read, and Stephen J. Vincent
}

\section{Key Points}

- Visual environment (or the quality of the retinal image) modulates the refractive development of the eye.

- Ocular response to form-deprivation and lens induced defocus is evident across a wide range of animal species, including humans.

- The visual system appears to be more sensitive to myopic than hyperopic defocus.

- Evidence suggests that greater time spent outdoors is protective against development and progression of myopia in children.

\subsection{Emmetropization and Normal Ocular Growth in Human Eyes}

When incident parallel rays of light from distant objects are brought to a focus upon the retina without accommodation, it is known as emmetropia. During postnatal eye growth, the precise matching of the axial length (the distance from the anterior corneal surface to the retina along the visual axis) and the optical power of the eye brings the eye to emmetropia [1,2]. This active regulatory process that harmonizes the expansion of the eye with the optical power of the cornea and the crystalline lens

R. Chakraborty $(\square)$

Flinders University, Adelaide, SA, Australia

e-mail: ranjay.chakraborty@ flinders.edu.au

\section{S. A. Read · S. J. Vincent}

Queensland University of Technology, Brisbane, QLD, Australia 
is known as emmetropization [1]. Any disruption to these highly coordinated ocular changes results in the development of refractive errors, wherein distant images are focused either behind (hyperopia) or in front (myopia) of the retina [1].

Human eyes exhibit a distinctive pattern of eye growth during the early period of visual development. The distribution of refractive errors at birth appears to be normally distributed [3, 4]. Apart from some exceptions [5], the majority of newborn infants are moderately hyperopic $(\sim+2.00$ to $+4.00 \mathrm{D})$ and this refractive error reduces significantly during the first 18 months of life [3, 6-8] (Fig. 4.1). By about 2-5 years of age, the distribution becomes leptokurtic with a peak around emmetropia to low hyperopia of about +0.50 to $+1.00 \mathrm{D}[5,6,8,11,12]$. Although studies have reported small reductions in hyperopic refraction until the middle to late teen years $[13,14]$, emmetropization is believed to be largely completed by $5-6$ years of age $[5,6,8,14]$.

Based on the visually guided ocular growth observed in a variety of animal models [15-17] (see Sect. 4.3), the growth of the human eye is also believed to be modulated by an active visual feedback from the hyperopic refractive error in neonatal eyes [18]. Studies have found a strong correlation between the rapid reduction in hyperopia and the changes in axial length during early ocular development [18, 19]. Human eyes are $\sim 17 \mathrm{~mm}$ long after birth and grow to about $20 \mathrm{~mm}$ after the first year $[11,18-20]$. This rapid expansion of the eye is largely attributed to the

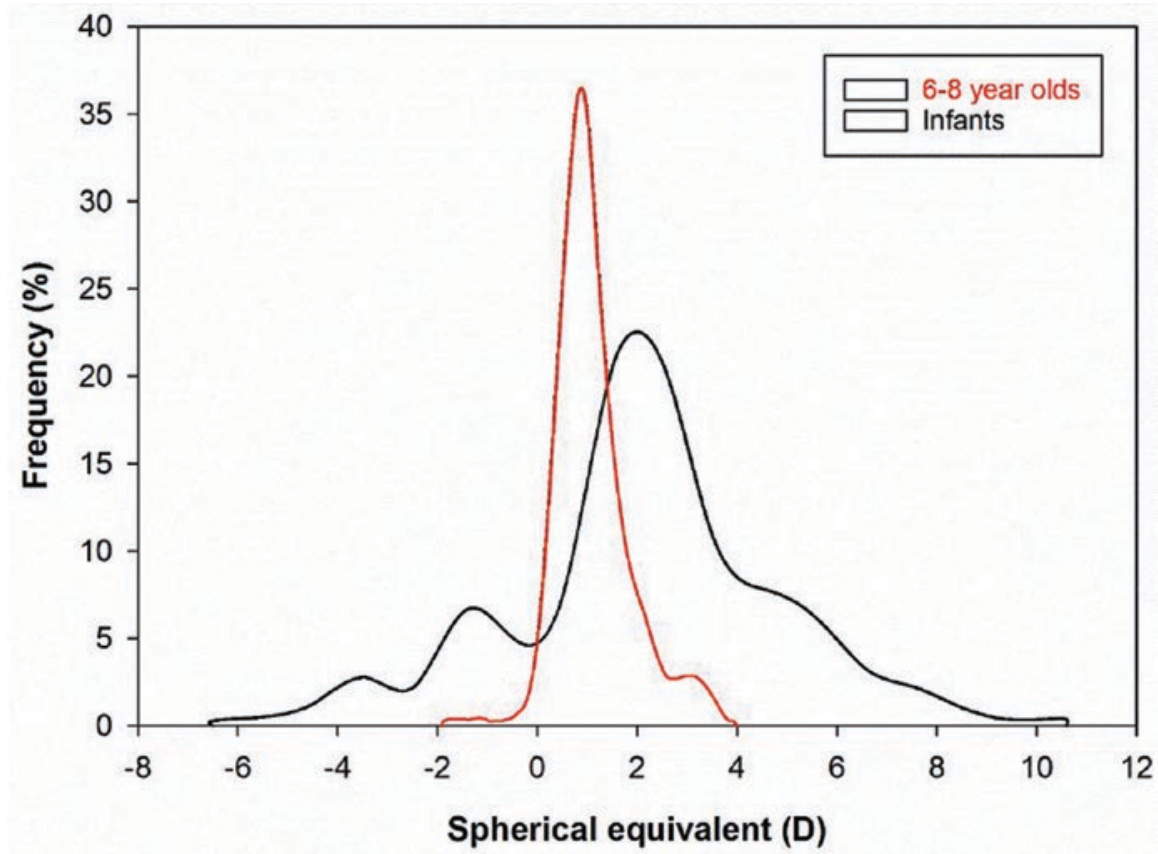

Fig. 4.1 Comparison of refractive error distribution among newborns [3] and 6-8-year-old children [9]. The distribution of refractive errors narrows between infancy to early childhood during the process of emmetropization. Adapted from FitzGerald and Duckman [10] 
expansion of the vitreous chamber $[18,21]$. From 2-3 years of age, axial elongation slows to approximately $0.4 \mathrm{~mm} /$ year until preschool age [11]. Consistent with changes in ocular refraction, the growth of the eye stabilizes further at 5-6 years, and only increases by $1-1.5 \mathrm{~mm}$ through the teenage years $[11,20,21]$. Together, these studies suggest that axial length is the most influential factor for emmetropization in human eyes.

In addition to changes in axial length, there is also a significant reduction in the refractive power of the cornea and the crystalline lens that contributes to the overall reduction in hyperopia in the first year of life [11, 18, 22]. Mutti et al. [18] reported a reduction of 1.07 and 3.62 D in corneal and crystalline lens powers, respectively, associated with flattening of the corneal and lens radii in newborn infants, between the ages of 3 and 9 months. Studies have also found higher degrees of corneal astigmatism in newborn infants [23-28], which reduces during the first 4 years of life and is associated with corneal flattening [24, 27, 29, 30]. Overall, these studies suggest that emmetropization in human eyes is largely attributed to the changes in axial length with minor contributions from corneal and crystalline lens powers.

Refractive errors occur as a result of either variations in (a) axial length with respect to the total refractive power of the eye (termed axial myopia or hyperopia) or (b) refractive power of the cornea and the crystalline lens with respect to the axial length of the eye (termed refractive myopia or hyperopia). This chapter focuses on the pathogenesis and potential underlying mechanisms of myopia, and the following section discusses the changes in different ocular parameters during myopic eye growth.

\subsection{Ocular Biometric Changes in Human Myopia}

As discussed earlier, the axial length of the eye is the primary biometric determinant of refractive error; however, the dimensions, curvature, and refractive index of each individual ocular structure contribute to the final refractive state. Ocular biometrics vary considerably throughout childhood, during the development and progression of myopia, and in response to clinical myopia control interventions.

\subsubsection{Cornea}

Several cross-sectional analyses have revealed a weak association between increasing corneal power (a steeper radius of curvature) and increasing levels of myopia [31-33], while others report no association [34], or the opposite relationship [35]. Longitudinal studies indicate that changes in corneal curvature during childhood [36-38] and early adulthood [39] are minimal and not associated with the magnitude of myopia progression. However, since the correlation between spherical equivalent refraction (SER) and the axial length to corneal radius ratio is typically stronger than that of axial length alone (by 15-20\%) [40-43], corneal curvature does appear to make a modest contribution to the magnitude of myopia. Although 
corneal thickness does not vary systematically with refractive error [44-47], a reduction in corneal hysteresis (an estimate of corneal biomechanical strength or viscoelasticity) has been observed with increasing levels of myopia in children [48, 49] and adults [50-52]. However, the causal nature of this relationship remains unclear, or if such corneal metrics correlate with posterior scleral biomechanics.

\subsubsection{Crystalline Lens and Anterior Chamber Depth}

While the cornea flattens substantially during infancy and then remains relatively stable throughout childhood, the crystalline lens continues to thin, flatten, and reduce in optical power until approximately 10 years (a $0.25-0.50 \mathrm{D}$ reduction per year), concurrent with lens fiber compaction [53-55]. These changes may be part of an emmetropization mechanism to compensate for continued axial elongation or a mechanical consequence of equatorial eye growth. Across a range of ethnicities, Mutti et al. [56] observed that within 1 year of myopia onset, compensatory crystalline lens thinning and flattening abruptly halted compared to children who remained emmetropic (Fig. 4.2), suggesting that childhood myopia is not purely axial in nature, but involves a decoupling of highly correlated anterior and posterior segment eye growth. In Singaporean children, Iribarren et al. [57] reported a transient acceleration in the reduction of lens power during myopia onset when the rate

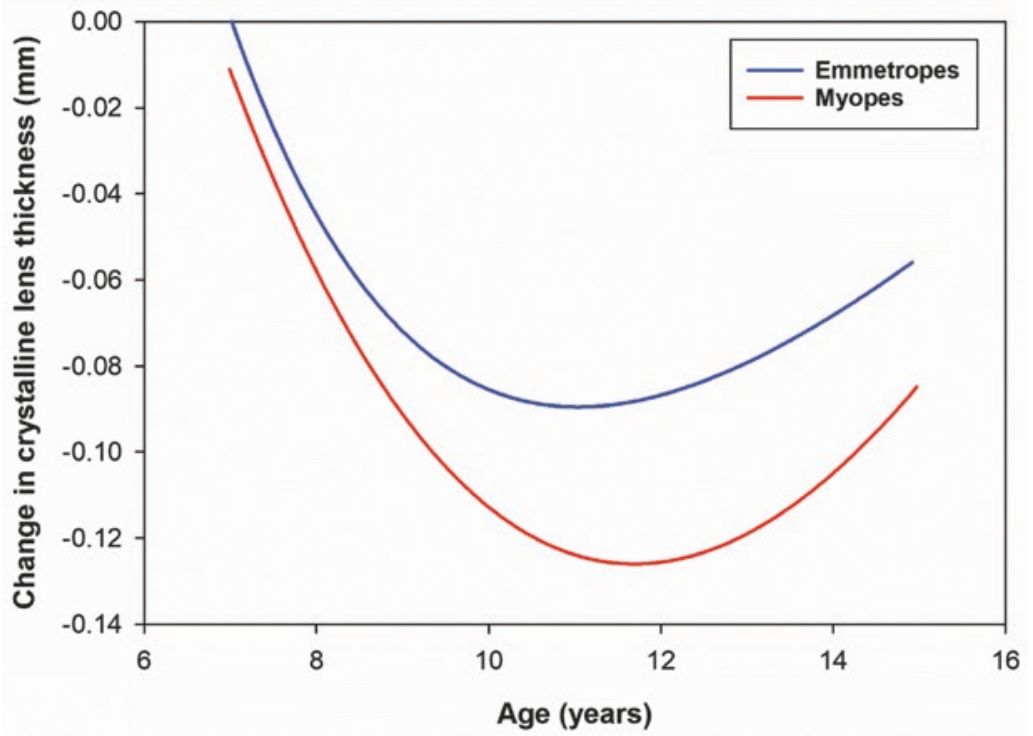

Fig. 4.2 The change in crystalline lens thickness as a function of age in myopes and emmetropes during childhood (after Mutti et al. [56]). Shortly after myopia onset (10-12 years), compensatory crystalline lens thinning abruptly halted compared to children who remained emmetropic suggesting that myopia development involves a decoupling of anterior and posterior segment eye growth 


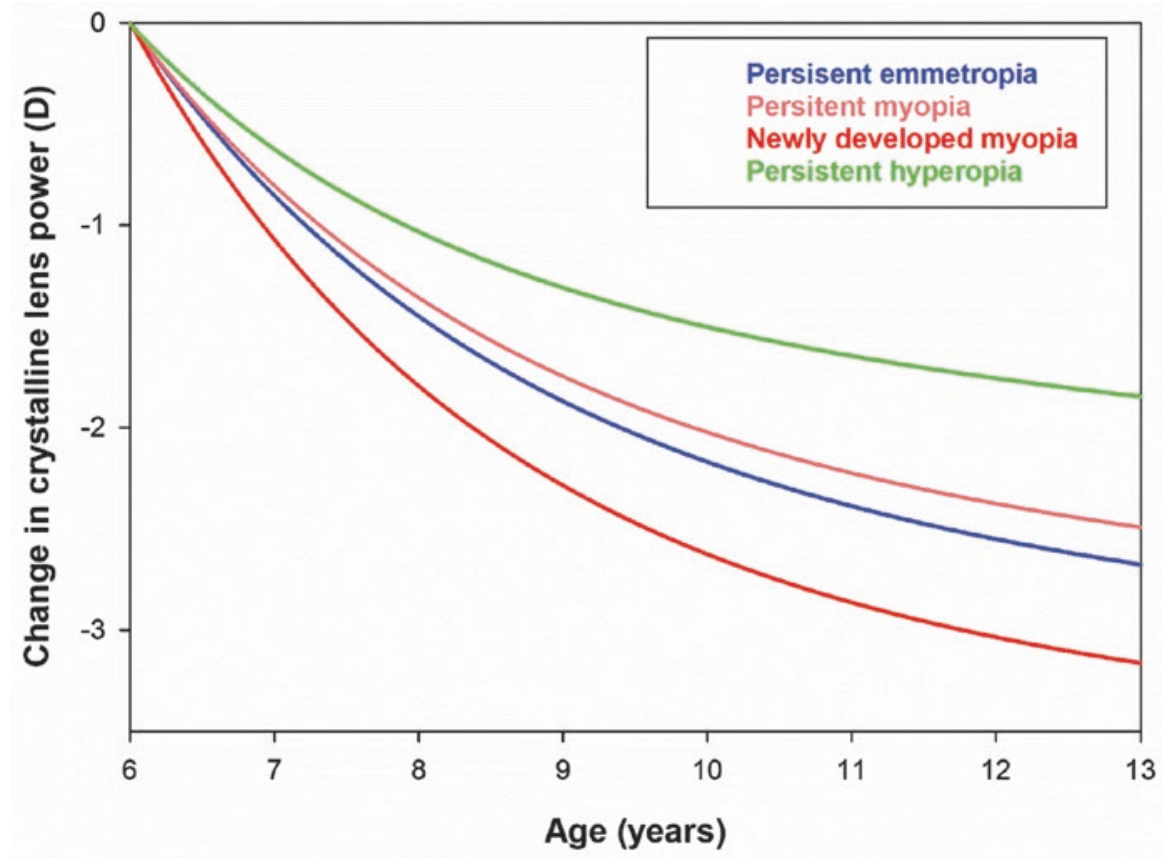

Fig. 4.3 The change in crystalline lens power during childhood (calculated from refraction and biometric measurements) in young Singaporean children for a range of refractive error groups (after Iribarren et al. [57]) The reduction in lens power increases during myopia onset (to a greater extent than other refractive error groups), but is not sustained throughout myopia progression

of axial growth was high, which was not sustained as myopia progressed (Fig. 4.3). Paradoxically, after 10 years of age, the lens continues to thicken and increase in curvature with the bedding down of additional fibers, but reduces in optical power, most likely due to a steepening of the gradient refractive index [58]. Changes in anterior chamber depth throughout childhood are inversely related to changes in lens thickness (as the lens thins, the anterior chamber deepens), and the anterior chamber is typically deeper in myopes compared to emmetropes and vice versa for the crystalline lens [53].

\subsubsection{Vitreous Chamber and Axial Length}

In contrast to the anterior segment, changes in the posterior segment (particularly, the vitreous chamber, choroid, and sclera) are more pronounced in myopic compared to non-myopic eyes (Fig. 4.4). Axial length, or more precisely, the vitreous chamber depth is the primary individual biometric contributor to refractive error in children, young adults, and the elderly [34,59,60], with the vitreous chamber depth accounting for over $50 \%$ of the observed variation in SER, followed by the cornea $(\sim 15 \%)$ and crystalline lens $(\sim 1 \%)$ [60]. Modeling of cross-sectional and 


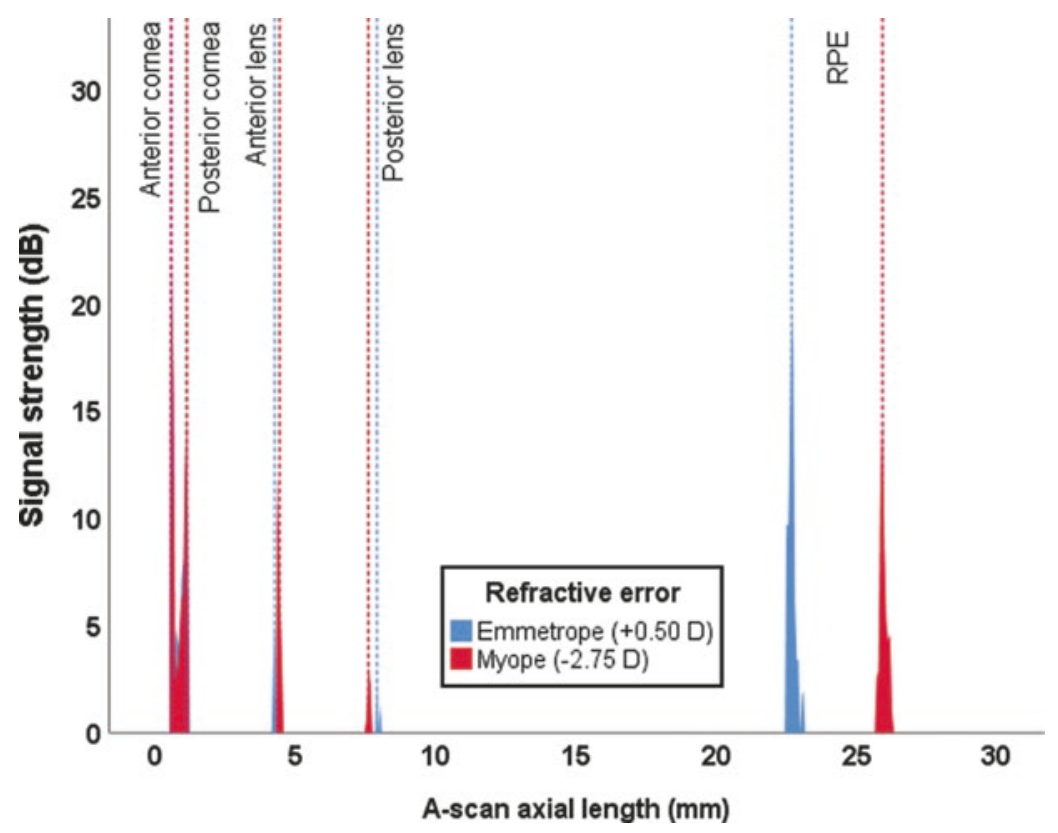

Fig. 4.4 Optical low coherence reflectometry A-Scan output from two 11-year-old males (one myope and one emmetrope). The predominant biometric differences are the deeper vitreous chamber (19.05 mm compared to $15.47 \mathrm{~mm})$ and the longer axial length $(25.87 \mathrm{~mm}$ compared to $22.69 \mathrm{~mm}$ ) in the myopic eye. The anterior chamber depth is slightly shallower in the emmetropic eye (by $0.13 \mathrm{~mm}$ ) while the crystalline lens is thicker (by $0.49 \mathrm{~mm}$ ) in comparison to the myopic eye. The corneal thickness varies by only $0.04 \mathrm{~mm}$

longitudinal data from emmetropic children indicates that axial length and vitreous chamber depth increase by approximately $0.16 \mathrm{~mm}$ per year from age 6-10 years, slowing to $0.05 \mathrm{~mm}$ per year from 11 to 14 years [61]. In myopic children aged between 6 and 11 years (corrected with single vision spectacles or contact lenses) average growth rates of approximately $0.30 \mathrm{~mm}$ per year have been reported [37, $62,63]$, with greater vitreous chamber and axial elongation observed in younger females with myopic parents [37]. A range of myopia control interventions significantly slow the rate of eye growth and myopia progression during childhood, in some cases by up to 50\% [64], and this reduction in axial elongation appears to be initially modulated by changes in the choroid underlying the retina.

\subsubsection{Choroid}

The choroid supplies the outer retina with oxygen and nutrients and regulates intraocular pressure and ocular temperature. The choroid is typically thinner in myopic compared to non-myopic eyes (most pronounced at the fovea $[65,66]$ ) and thins with increasing myopia and axial length in both adults [67-74] and children [7577]. Significant choroidal thinning is also observed in high myopia $(<-6.00 \mathrm{D})$ or 
eyes with posterior staphyloma [78], and has been associated with the presence of lacquer cracks [79], choroidal neovascularization [80], and reduced visual acuity [81]. The choroid also appears to be a biomarker of ocular processes regulating eye growth given that the central macular choroid thins during the initial development and progression of myopia [82-84] and thickens in response to imposed peripheral myopic retinal image defocus $[85,86]$, topical anti-muscarinic agents $[87,88]$, and increased light exposure [89] (clinical interventions associated with a slowing of eye growth in children).

\subsubsection{Sclera}

Scleral thinning associated with axial myopia is primarily restricted to the posterior pole [90-92], due to scleral tissue redistribution [93]. Scleral thinning may alter the tissue strength surrounding the optic nerve head, rendering myopic eyes more susceptible to glaucomatous damage [94, 95]. Consequently, posterior reinforcement surgery using donor scleral tissue has been refined over the years to arrest further axial elongation and scleral thinning in highly myopic eyes [96, 97]. Although anterior scleral thickness is similar between myopic and non-myopic eyes [98-100], there is growing evidence that the anterior sclera thins slightly during accommodation, particularly in myopic eyes [101, 102], most likely due to biomechanical forces of the ciliary muscle. A greater thinning observed in myopic eyes may be a result of a thicker posterior ciliary muscle [103-105] or changes in biomechanical properties of the sclera reported in animal models of form-deprivation myopia [106, 107].

\subsection{Visual Environment, Emmetropization, and Myopia: Evidence from Animal Models}

Over the last four decades, numerous animal models have provided valuable insight into the mechanisms underlying emmetropization and refractive error development. Much of the knowledge on vision-dependent changes in ocular growth has emanated from animal experiments in which either the quality of image formed on the retina is degraded (known as form-deprivation [FD]), or the focal point of the image is altered with respect to the retinal plane (known as lens induced defocus). Both FD and lens induced defocus result in abnormal eye growth and development of refractive errors. This section summarizes the attributes of experimental ametropias derived from these two visual manipulations, their differences, and significance for understanding refractive error development in humans.

\subsubsection{Form-Deprivation Myopia}

FD is the most commonly used experimental paradigm to model axial myopia in animals. Depriving the retina of form or patterned vision through eyelid suture 
Fig. 4.5 Ocular

compensation for

form-deprivation (FD). (a)

A diffuser causes

nondirectional blur and a

reduction in contrast of the

retinal image. (b) The

absence of visual feedback

related to the effective

refractive state of the eye

causes a thinning of the

posterior choroid and an

increase in ocular growth,

resulting in myopia

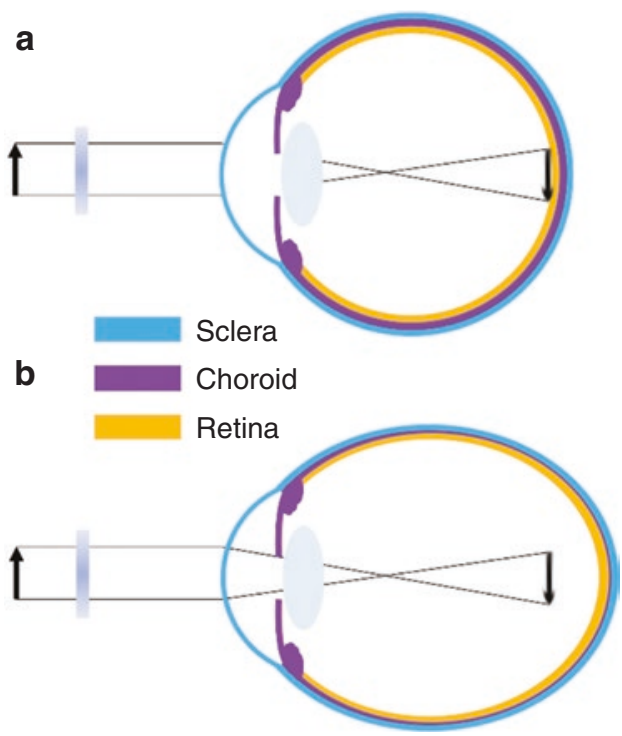

[108-110], or translucent diffusers [2, 15, 111-114] consistently produces axial myopia (Fig. 4.5). The use of noncontact translucent diffusers offers a more reliable representation of ocular changes with FD since they do not induce corneal changes (unlike eyelid fusion techniques). The ocular changes observed in response to FD clearly illustrate that degrading retinal image quality can produce robust myopic changes. Schaeffel et al. [115] proposed that FD is an open-loop condition, in which myopia develops as a result of uncoordinated ocular growth due to reduced retinal image contrast (or mid-range spatial frequency vision) [116] and the absence of visual feedback related to the effective refractive state of the eye [117].

The myopic response to FD varies among different animals. It is generally greatest in chickens ( -9 D after 5 days of FD) [118], followed by tree shrews ( -8 D after 12 days in young animals) [119] and guinea pigs (-6.6 D after 11 days) [113], and is less pronounced and much more variable in marmosets $(-8 \mathrm{D}$ after 4.5 weeks) [120] and rhesus monkeys ( -5 to $-6 \mathrm{D}$ after 17 weeks) [121, 122]. Variations observed between individual studies and animal models may be due to differences in experimental paradigms, the duration and extent of FD, inherent ocular anatomical variations, and/or differences in susceptibility to environmental myopia. Nevertheless, the myopic response to FD is conserved across a wide range of animal species (including fish, rabbit, mouse, and kestrel) [123]. In all species, axial myopia is predominantly caused by a significant elongation of the vitreous chamber, along with thinning of the choroid and the sclera [16, 17, 113, 124-132]. Few studies have also reported changes in corneal curvature and lens thickness with FD [131, 133-135]. Interestingly, ocular conditions that cause varying degrees of visual deprivation in humans such as ptosis [136], congenital cataract [137], corneal opacity [138], and vitreous hemorrhage [139] are associated with myopia, which may result from mechanisms similar to FD myopia observed in animals. 
FD myopia is a graded phenomenon, where increasing degrees of image degradation are positively correlated with the magnitude of induced axial myopia [129, 140]. In addition, the effects of FD declines with age. Younger chicks [141, 142], macaques [143], tree shrews [119], and marmosets [144] show greater ocular changes in response to image degradation compared to older animals, potentially due to age-related reductions in sensory processing of blur stimuli or changes in scleral growth [144].

\subsubsection{Lens Defocus Ametropias}

Perhaps the strongest evidence of visual regulation of ocular growth comes from animal studies that show eyes can actively compensate for artificially induced myopic and hyperopic defocus by adjusting the axial length to the altered focal plane (i.e., emmetropization through the treatment lenses) (Fig. 4.6) [145]. Myopic defocus with plus lenses simulates artificial myopia that leads to a thickening of the choroid (moving the retina forward) and a reduction in the overall growth of the eye, thus, causing a hyperopic refractive error. Conversely, hyperopic defocus with minus lenses induces artificial hyperopia that leads to a thinning of the choroid

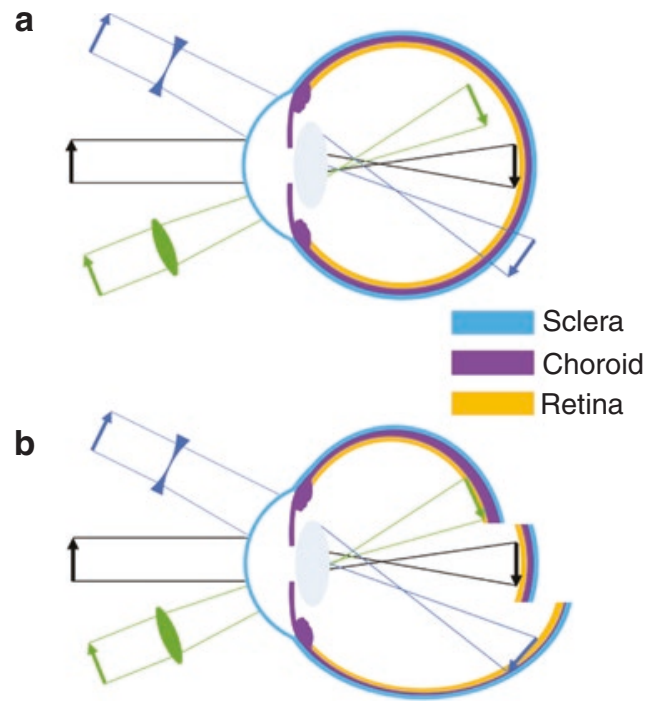

Fig. 4.6 (a) Schematic of imposed lens defocus. With no lens (black arrow), incident parallel rays of light from distant objects are focused on the retina. A plus lens (green, convex) causes the retinal image to focus in front of the retina known as myopic defocus, whereas a minus lens (blue, concave) focuses the image behind the retina known as hyperopic defocus. (b) A normal eye with no imposed lens defocus (black) exhibits normal ocular growth and choroidal thickness. Myopic defocus with plus lenses (green) causes a thickening of the choroid (moving the retina forward) and a reduction in the overall growth of the eye, causing a hyperopic refractive error. Hyperopic defocus with minus lenses (blue) leads to a thinning of the choroid (moving the retina backward) and an increase in ocular growth, resulting in myopia. Adapted from Wallman J and Winawer J, 2004 [1] 
(moving the retina backward) and an increase in ocular growth, resulting in myopia to re-establish the optimal refractive state. This phenomenon was first documented in chicks [145], and has been extensively studied in chicks [16, 17, 146-148], tree shrews [149], rhesus monkeys [15, 150], marmosets [151], guinea pigs [152, 153], and mice [154] thereafter, indicating that the mechanisms regulating ocular growth can distinguish the sign of the imposed defocus in a wide range of animal species.

Chick eyes can compensate for a remarkable range of +15 to $-10 \mathrm{D}$ of imposed defocus $[16,147]$. However, the operating range of defocus is much smaller for other animal species (monkey: -2 to +8 D [15], marmosets: -8 to <+4 D [151], tree shrew: -10 to +4 D [155], guinea pig: -7 to +4 D) $[152,156]$. Compared to birds, the inability of primates to compensate for greater magnitudes of defocus may be due to bigger eye size $[15,150]$, the process of emmetropization [150], differences in the accommodative response to defocus stimuli, and/or the degree of independent accommodation between fellow eyes $[15,150,157]$. In all animals, the axial response to lens induced defocus is dependent upon the power of the treatment lens [147, 149-152, $158]$, and is predominantly attributed to the changes in vitreous chamber depth [16, $147,159]$. Similar to FD, the ocular response to lens induced defocus decreases with age [16]. Recent evidence suggests that the human visual system may also be able to detect the sign and magnitude of imposed defocus and make compensatory changes in axial length, similar to other animals. A number of studies have reported small bidirectional changes in axial length and choroidal thickness in response to $1-2 \mathrm{~h}$ of myopic and hyperopic defocus in children and young adults [160-165].

Studies have shown that the biological mechanisms underlying alterations in ocular growth to myopic and hyperopic defocus may be completely different (and not merely opposite to each other), and that the visual system is perhaps more sensitive to myopic defocus $[166,167]$. In fact, the ocular response to lens induced defocus depends on the frequency and duration of lens wear, and not simply the "total duration" per day [166-169]. These findings argue for a nonlinear processing of myopic and hyperopic defocus signals across the retina [166, 167].

\subsubsection{Comparing Form-Deprivation and Lens Defocus}

Although FD and lens induced defocus use different visual stimuli to induce compensatory changes in ocular growth, there are features that are common to both visual manipulations. Removal of the visual manipulation triggers "recovery" from both FD and lens induced defocus [16, 17, 170]. During this recovery phase, the eyes quickly return to emmetropia by reversing the changes in choroidal thickness and axial eye growth (mainly by changing the vitreous chamber depth) $[16,17,119$, 150, 151, 170-173].

Further evidence from animal work suggests that the elimination of accommodation by cycloplegia, ciliary nerve section or damage to the Edinger-Westphal nucleus does not prevent the response to imposed FD [145, 174] or lens induced defocus $[148,175]$. These results suggest that intact accommodation is not essential for visually guided growth [176] or there might be another accommodative pathway (not through ciliary and iris sphincter muscles) underlying optical defocus induced alterations in ocular growth [175]. 
Other studies argue that mechanisms underlying the response to FD and lens induced defocus may not be the same [177]. Some studies show different light paradigms selectively disrupt the response to FD or lens induced defocus [178-180]. For instance, high luminance levels inhibit myopia caused by FD in monkeys and chicks, but only slow the response to negative lenses $[181,182]$. Furthermore, dopamine (a strong ocular growth inhibitor, see Sect. 4.4.1) may not signal eye growth in a similar manner for these two forms of experimental myopia [183]. While most studies indicate that dopamine agonists block increased axial elongation [177], one study reported that dopamine agonists inhibit FD, but not lens-induced myopia in guinea pigs [184]. More studies are needed to determine if these contradictory results are due to different regulatory mechanisms of eye growth or other parameters of the experimental paradigm.

\subsection{Other Visual Cues for Emmetropization}

Whilst the clarity of the retinal image dominates the nature of ocular growth, other visual cues may also influence the process of emmetropization. This section examines some of the important cues that could significantly affect retinal image quality, and hence ocular growth in human eyes.

\subsubsection{Retinal Physiology}

Work from animal models suggests that retinal defocus (or visual blur) initiates a signaling cascade that leads to a number of cellular and biochemical changes in the retina and the retinal pigment epithelium (RPE), which signal changes to the choroid, and eventually the sclera, leading to alterations in the overall growth and refractive state of the eye (Fig. 4.7) [16, 17, 185]. The retina is an integral part of this visual signaling as it is the first layer of photosensory neurons that detect

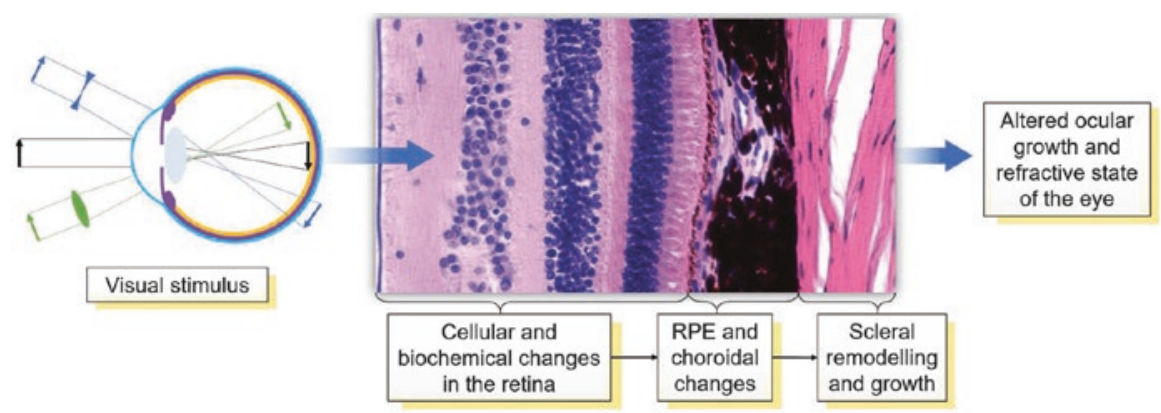

Fig. 4.7 A biochemical signal cascade beginning at the retina and ending at the sclera regulating ocular growth and the refractive state. Retinal defocus may initiate a signaling cascade that leads to a number of cellular and biochemical changes in the retina and the retinal pigment epithelium (RPE), the choroid, and eventually the sclera, leading to alterations in the overall growth and the refractive state of the eye 
defocus [186]. Furthermore, ocular compensation for both FD and lens induced defocus are largely regulated at the retinal level. Severing the optic nerve in young chicks does not prevent the development of refractive errors in response to spectacle lenses [16, 187] or diffusers [130]. In both chicks [17, 188, 189] and primates [190], partial diffusers and hemifield spectacle lenses restricted to only half of the visual field cause corresponding myopic changes only in the visually deprived part of the globe. These studies demonstrate that the visual regulation of ocular growth in response to diffusers and lenses primarily occurs within the retina, with minimal input from the brain.

Retinal neurons also secrete a number of growth regulatory neurotransmitters (such as dopamine [191, 192], retinoic acid [153], nitric oxide [193, 194] and glucagon [195]) that can directly alter ocular growth in mammalian eyes. Dopamine, one of the most widely studied neurotransmitters with regard to myopia in animal models, has been implicated as a potent stop signal for myopic eye growth [183, 196]. In both chickens [191, 197] and primates [198], FD myopia is associated with lower levels of 3,4-dihydroxyphenylacetate (DOPAC, the primary metabolite of dopamine) and dopamine in the retina. Although the protective effects of outdoor light exposure on myopia development in children has been hypothesized to be mediated by greater dopamine synthesis in the eye (see Sect. 4.5), the exact mechanisms underlying the protective effects of dopamine on myopia are not fully known. Together, these studies suggest that alterations in normal retinal physiology and/ or changes in retinal neurotransmitters may lead to the development of refractive errors, as shown in chickens [186, 199, 200] and mice [201-206]. Some features of retinal abnormalities and refractive errors are evident in humans as well; for instance, NYX [207] and GRM6 [208] retinal ON pathway mutations and retinal degenerations such as cone-rod dystrophy [209] and retinitis pigmentosa [210] are associated with myopia.

\subsubsection{Aberrations}

A long held belief is that myopia may develop due to the eye's emmetropization response to inherent ocular aberrations that degrade retinal image quality and trigger axial elongation [211]. Since there is minimal variation in longitudinal chromatic aberration between individuals or refractive error groups in humans [212], most investigations have focused on monochromatic higher order aberrations (HOAs) as a potential myopigenic stimulus. Evidence concerning the relationship between HOAs during distance viewing and refractive error from cross-sectional studies is conflicting [211, 213]. However, during or following near work tasks, adult myopic eyes tend to display a transient increase in corneal and total ocular HOAs (Figs. 4.8 and 4.9), suggesting a potential role for near work induced retinal image degradation in myopia development $[214,215]$. Longitudinal studies of myopic children also indicate that eyes with greater positive spherical aberration demonstrate slower eye growth $[63,216]$. 


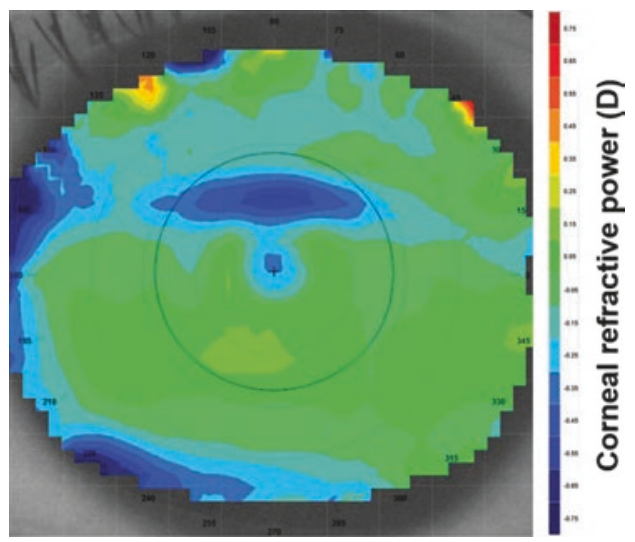

Fig. 4.8 Corneal refractive power difference map following a 10 min reading task at $25^{\circ}$ downward gaze. The black circle denotes the pupil outline detected by the video keratoscope. A horizontal band of corneal flattening is observed in the superior aspect of the pupil corresponding to the position of the upper eyelid during downward gaze. This refractive change is equivalent to a $0.20 \mathrm{D}$ hyperopic shift over the central $4 \mathrm{~mm}$
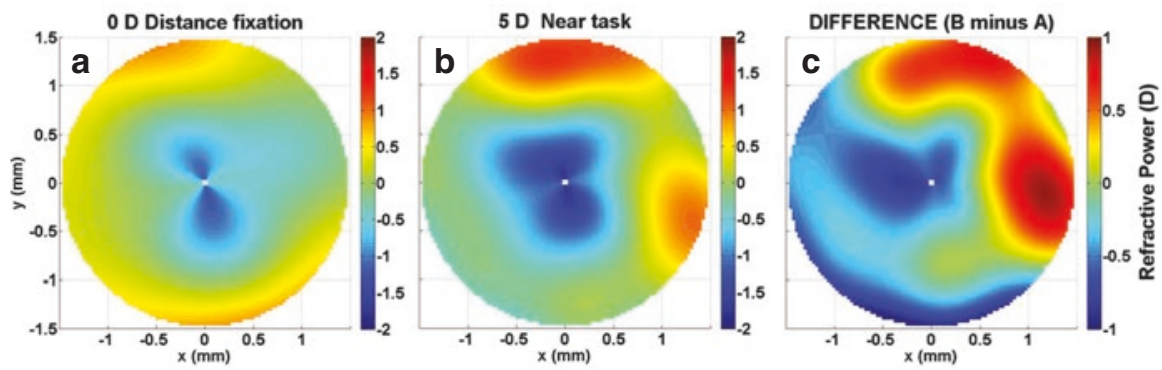

Fig. 4.9 Refractive power maps, a graphical representation of total ocular higher order aberrations, during (a) distance fixation (0 D accommodation demand), (b) a $5 \mathrm{D}$ accommodation task, and (c) the difference (B minus A) over a $3 \mathrm{~mm}$ pupil diameter. A significant increase in negative spherical aberration of $-0.10 \mu \mathrm{m}$ is displayed

A number of myopia control interventions also alter the HOA and peripheral refraction profile. While relative peripheral refraction was initially thought to modulate central eye growth, recent longitudinal studies have found no association between peripheral refraction and myopia progression in children [217, 218]. Multifocal soft contact lenses and orthokeratology significantly increase the magnitude of positive spherical aberration [219, 220]. The anticholinergic agent atropine may also provide visual feedback that influences eye growth due to an increase in positive spherical aberration or horizontal coma associated with cycloplegia and pupil mydriasis, respectively [221]. Collectively, these findings suggest that changes in HOAs may influence eye growth and refractive development during childhood. 


\subsubsection{Accommodation}

Given the association between near work and the development and progression of childhood myopia [222], numerous studies have compared various characteristics of accommodation between refractive error groups, typically the accuracy of the accommodation response, since a lag of accommodation (hyperopic retinal defocus) may stimulate axial elongation as observed in animal models. Using a range of experimental approaches, the accommodative response to a $3 \mathrm{D}$ accommodative stimulus is $\sim 0.25$ to $1.00 \mathrm{D}$ less in myopic adults compared to emmetropes [223227]. The slowing of myopia progression during childhood with progressive addition or bifocal lenses, designed to improve accommodation accuracy and minimize a lag of accommodation, adds some weight to the role of accommodation in myopia development and progression [62, 228]. However, the exact underlying mechanism of myopia control with such lenses may be related to imposed peripheral retinal defocus or a reduction in the near vergence demand [229]. In a longitudinal study of young infants [230], a significant relationship was observed between the accommodative response and the reduction in neonatal refractive error in the first 2 years of life, supporting a potential role for accommodation-guided eye growth.

\subsubsection{Circadian Rhythms}

Like many of the human body's physiological processes, numerous ocular structures and functions exhibit cyclic variations over the course of the day. Visual inputs such as daily patterns of light exposure are considered critical factors in entraining the timing of these circadian rhythms. Findings from animal studies demonstrate that normal eye growth exhibits significant circadian variations, with the eye generally being longest during the day and shorter at night [231]. Choroidal thickness also exhibits a circadian rhythm in normal eyes, which is generally in antiphase to the rhythms in axial length [172]. Similar patterns of diurnal variation in axial length and choroidal thickness have also been documented in normal human eyes [232-234].

It has also been suggested that ocular circadian rhythms may play a role in eye growth regulation and the development of myopia, since altering the visual inputs that drive circadian rhythms (e.g., rearing animals in constant light [235] or constant darkness [236], or exposing the eye to bright light at night time [237]) can result in alterations in normal eye growth in animal models. Furthermore, when refractive errors (both hyperopic and myopic) are induced experimentally in animals, changes in the magnitude and phase of the normal circadian rhythms of axial length and choroidal thickness also occur, which also supports a potential role of circadian rhythms in the development of refractive errors [172, 238]. These findings from animal research were paralleled by studies in young adult humans, where changes in the normal diurnal rhythms of axial length and choroidal thickness occurred in response to short-term (12-h) exposure to monocular myopic [165], and hyperopic blur [163]. Although the exact role played by circadian rhythms in the regulation of 
human eye growth is not fully understood, human studies also indicate that myopes exhibit alterations in their systemic melatonin levels [239], and also exhibit altered sleep patterns [240] compared to non-myopic individuals.

\subsection{Effects of Key Environmental Factors on Myopia}

As discussed in Chaps. 1 and 2, myopia represents a "complex" disorder with both environmental and genetic origins [241, 242]. This section discusses some of the important environmental factors, and their influence on myopia.

\subsubsection{Near Work and Education}

Since the age when myopia normally develops and progresses coincides with the school years, myopia has long been suggested to be connected with increased levels of education. Indeed, numerous studies conducted across a range of different populations have consistently found that higher levels of education are associated with a higher prevalence of myopia [243-245]. The exact mechanism linking increased education with myopia, however, is less clear. Although it is possible that optical [214, 224] or biomechanical [246, 247] ocular changes associated with near work could potentially promote myopic eye growth in those with higher levels of education (and hence near work demands), population studies examining the link between near work activities and myopia have been conflicting, with some studies suggesting an association between near work and myopia [222, 248], and others indicating no significant effects [249]. The relatively inconsistent findings linking near work with myopia development suggests a potential role for other factors in the association between education and myopia, such as a lack of outdoor light exposure, discussed further below.

\subsubsection{Urbanization}

Aspects of the living environment may also be involved in the development and progression of myopia, since population-based studies consistently report a higher prevalence of myopia in children living in urban regions, compared to children living in rural regions [250, 251]. These associations between the urban environment and myopia could at least partially be explained by socioeconomic and educational differences between urban and rural regions, which could in turn result in differences in near work and outdoor activities. However, a number of recent studies indicate that a higher population density is significantly associated with increased myopia prevalence in children, independent of near work and outdoor activities [252, 253]. This suggests other aspects of the urban environment may potentially impact upon eye growth. Studies have also reported associations between housing type and myopia, with children living in smaller homes reported to have a significantly higher 
prevalence of myopia [253, 254]. Although further research is required to establish the causative nature and mechanisms underlying these associations, it has been hypothesized that a constricted living space may result in an increased exposure to hyperopic blur, thus promoting myopia.

\subsubsection{Light Exposure}

A number of recent studies report that the time children spend engaged in outdoor activities is negatively associated with their risk of myopia [241, 249, 255-259]. Both cross-sectional and longitudinal studies indicate that greater time spent outdoors is associated with a significantly lower myopia prevalence and reduced risk of myopia onset in childhood. Although some studies report significant associations between myopia progression and outdoor activity [257, 259], this is not a consistent finding across all longitudinal studies [260]. A recent meta-analysis of studies examining the relationship between outdoor time and myopia indicated that there was a $2 \%$ reduction in the odds of having myopia for each additional hour per week spent outdoors [261].

These associations [241, 255, 256] have prompted recent interest in the potential influence of light exposure in the regulation of eye growth and myopia. Since outdoor activity typically involves exposure to high intensity light, it has been hypothesized that increased exposure to bright light may be the important factor underlying these protective effects of outdoor activity [256]. Other factors, such as the typical pattern of retinal focus experienced in outdoor environments (which is likely to involve less near focusing and potentially less exposure to hyperopic blur), may also play a role [262].

Light Intensity and Myopia Animal studies indicate that the intensity of daily light exposure can influence refractive development. In normal growing young chickens, rearing animals under a normal daily light-dark cycle, but with daily bright ambient lighting $(\sim 10,000$ lux $)$ resulted in significantly less myopic refractive errors than when animals were reared under dim ambient lighting during the day (50 lux) [263]. Bright light exposure also inhibits the development of FD myopia in a range of different animal species [114, 181, 264], with the strength of inhibitory effects correlating significantly with the log of the intensity of ambient light exposure [264]. The effects of increased light intensity upon lens induced myopia (through imposing hyperopic defocus) in animals however are less consistent, with either a slowing of lens compensation (with no change in refractive endpoint) [182], or no significant effects on lens compensation reported [265].

Recent observational longitudinal studies in humans utilizing wearable light sensors to assess ambient light exposure have enabled the relationship between light exposure and axial eye growth in childhood to be examined [266, 267]. Similar to findings in animals, both of these recent studies have reported that slower axial eye growth is associated with greater daily ambient light exposure (with a 1-log unit 
increase in light exposure being associated with $\sim 0.1 \mathrm{~mm} /$ year slower axial eye growth), with this relationship reaching statistical significance in the study with the larger sample size $(n=102)$ [266], and bordering on significance $(p=0.07, n=60)$ in the other study [267]. A recent randomized, controlled trial in Taiwan examined the effect of increasing outdoor time during the school day (an extra $40 \mathrm{~min}$ of outdoor time during school recess) upon myopia development and axial eye growth over 12 months [268]. In this study, light exposure was also monitored using wearable light sensors, and a significant association between greater light exposure and slower myopia progression was also documented. Collectively, these studies suggest that increased light exposure is associated with slower axial eye growth in the human eye.

Increased light exposure may also underlie some of the differences in myopia prevalence found in different geographic locations. A recent study compared the habitual ambient light exposure (captured with wearable light sensors) of children living in Singapore (a country with some of the highest reported levels of childhood myopia prevalence [269]) with children living in Australia (where myopia prevalence is generally reported to be relatively low [270]) and found substantially lower levels of outdoor light exposure in the children living in Singapore (Fig. 4.10) [271].

Duration of Light Exposure and Myopia Animal studies examining the effects of increased light exposure upon myopia development have generally used experimental paradigms where elevated light levels were applied continuously for the full day. Lan et al. [272] examined the influence of different daily durations of bright light exposure upon inhibition of myopia in chickens. They found bright light applied for

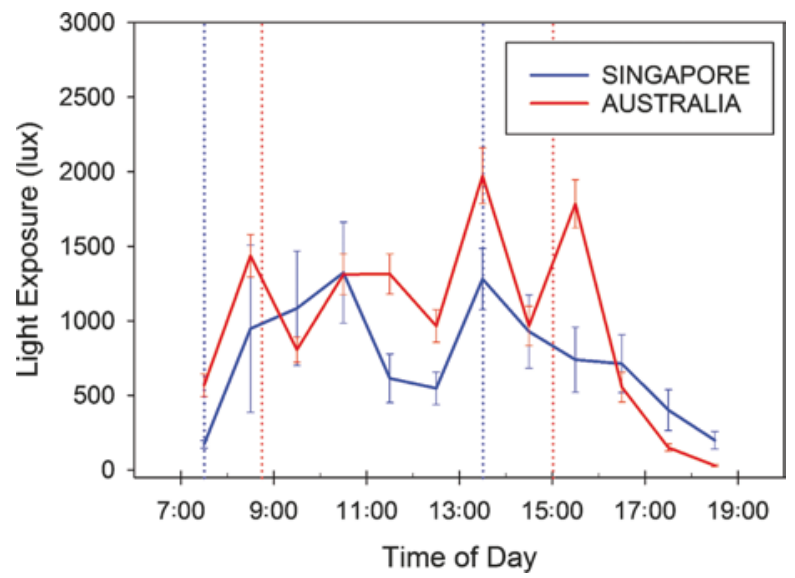

Fig. 4.10 Average hourly light exposure of Australian (red lines) and Singaporean (blue lines) children assessed during school weekdays using wearable light sensors. Note the substantially greater light exposure for the Australian children at a number of periods throughout the day [271]. This lower daily exposure to bright outdoor light may be one factor underlying the higher myopia prevalence typically observed in Singaporean children. Dashed lines indicate the average school start and finish times in Australia (red) and Singapore (blue). Error bars represent the standard error of the mean 
only 1 or $2 \mathrm{~h}$ per day did not inhibit myopia, but $5 \mathrm{~h}$ of exposure did significantly protect against the development of FD myopia. Extending exposure duration further to $10 \mathrm{~h}$ per day did not appear to offer further protective benefit.

In a large longitudinal study, Jones et al. [249] reported that children who engaged in outdoor activities for $14 \mathrm{~h}$ per week or more, exhibited the lowest odds of developing myopia. A number of recent randomized controlled trials have reported that interventions that increase children's outdoor time (by 40-80 min a day) significantly reduce the onset of myopia in childhood [268, 273, 274]. In the "Role of outdoor activity in myopia study" [266], children who were habitually exposed to low ambient light levels (on average less than 60 min exposure to outdoor light per day) had significantly faster axial eye growth compared to children habitually exposed to moderate and high light levels. These findings from human studies suggest that children who are exposed to less than $60 \mathrm{~min}$ a day of bright outdoor light are at an increased risk of more rapid eye growth and myopia development, and that approximately $2 \mathrm{~h}$ or more of outdoor exposure each day is required to provide protection against myopia development in the human eye.

Spectral Composition of Light and Myopia Since the spectral characteristics of outdoor light are significantly different to typical indoor light, it has been suggested that the spectral composition of outdoor light may be an additional factor that underlies the protective effects of outdoor activity upon myopia development. Although some studies in humans suggest exposure to short-wavelength light may protect against myopia [275], there has only been limited work in humans examining the possible impact of the spectral composition of light on myopia.

Animal studies do suggest that the spectral content of light can influence the growth of the eye, since altered eye growth is observed in animals reared under narrow band spectral lighting conditions. However, the effects of the spectral content of light shows substantial interspecies differences [276-279]. In chickens and guineas pigs, raising animals in short-wavelength light appears to slow eye growth and reduce myopia development, whereas long-wavelength light appears to increase eye growth and lead to myopia development [276, 279]. Conversely long-wavelength light appears to slow eye growth and reduce myopia development in tree shrews and rhesus monkeys [277, 278]. Further research is required to understand the mechanisms underlying these effects (and interspecies differences) and to establish the impact of the spectral composition of light upon human myopia.

\subsection{Conclusion}

In conclusion, over the last 40 years, remarkable progress has been made in understanding the possible mechanisms and pathogenesis of myopia, with a large contribution to this knowledge coming from an extensive body of work in animal models. Importantly, laboratory research in animals have shown that the visual environment 
(i.e., quality and/or focus of the retinal image) influences ocular growth and refractive development, which has been a key to our current understanding of the process of emmetropization in humans. Similarities in features of defocus induced ocular changes in humans and experimental models of myopia, such as the eye's ability to detect the sign of retinal defocus and make compensatory changes in axial length, suggest that mechanisms of visually guided eye growth and refractive error development in animal models may be present in human eyes as well. Alongside animal research, a large body of clinical and epidemiological research has identified a number of other visual cues (e.g., aberrations, accommodation, and circadian rhythms) and environmental factors (e.g., light exposure, near work, and education) that could affect normal ocular growth and lead to the development of refractive errors. Experimental models continue to provide valuable information on cellular and biochemical mechanisms of eye growth, enabling the identification of potential new therapeutic targets for early diagnosis and treatment of myopia.

\section{References}

1. Wallman J, Winawer J. Homeostasis of eye growth and the question of myopia. Neuron. 2004;43:447-68.

2. Smith EL. Spectacle lenses and emmetropization: the role of optical defocus in regulating ocular development. Optom Vis Sci. 1998;75:388-98.

3. Cook RC, Glasscock R. Refractive and ocular findings in the newborn. Am J Ophthalmol. 1951;34:1407-13.

4. Banks MS. Infant refraction and accommodation. Int Ophthalmol Clin. 1980;20:205-32.

5. Mohindra I, Held R. Refraction in humans from birth to five years. In: Third International Conference on Myopia Copenhagen, August 24-27, 1980. New York: Springer; 1981. p. $19-27$.

6. Ingram R, Barr A. Changes in refraction between the ages of 1 and $31 / 2$ years. Br J Ophthalmol. 1979;63:339-42.

7. Wood I, Hodi S, Morgan L. Longitudinal change of refractive error in infants during the first year of life. Eye. 1995;9:551-7.

8. Gwiazda J, Thorn F, Bauer J, Held R. Emmetropization and the progression of manifest refraction in children followed from infancy to puberty. Clin Vis Sci. 1993;8:337-44.

9. Kempf GA, Collins SD, Jarman BL. Refractive errors in the eyes of children as determined by retinoscopie examination with a cycloplegic. Results of eye examinations of 1,860 white school children in Washington, DC. Public Health Bulletin. 1928;182:56.

10. Fitzgerald DE, Duckman R. Refractive error. In: Visual development, diagnosis, and treatment of the pediatric patient. Philadelphia: Lippincott Williams \& Wilkins; 2006. p. 69-88.

11. Gordon RA, Donzis PB. Refractive development of the human eye. Arch Ophthalmol. 1985;103:785-9.

12. Saunders KJ. Early refractive development in humans. Surv Ophthalmol. 1995;40:207-16.

13. Hirsch MJ. Predictability of refraction at age 14 on the basis of testing at age 6-interim report from the Ojai Longitudinal Study of Refraction. Optom Vis Sci. 1964;41:567-73.

14. Zadnik K, Mutti DO, Friedman NE, Adams AJ. Initial cross-sectional results from the Orinda Longitudinal Study of Myopia. Optom Vis Sci. 1993;70:750-8.

15. Smith EL, Hung LF. The role of optical defocus in regulating refractive development in infant monkeys. Vis Res. 1999;39:1415-35.

16. Wildsoet C, Wallman J. Choroidal and scleral mechanisms of compensation for spectacle lenses in chicks. Vis Res. 1995;35:1175-94. 
17. Wallman J, Wildsoet $\mathrm{C}, \mathrm{Xu}$ A, et al. Moving the retina: choroidal modulation of refractive state. Vis Res. 1995;35:37-50.

18. Mutti DO, Mitchell GL, Jones LA, et al. Axial growth and changes in lenticular and corneal power during emmetropization in infants. Invest Ophthalmol Vis Sci. 2005;46:3074-80.

19. Pennie FC, Wood IC, Olsen C, White S, Charman WN. A longitudinal study of the biometric and refractive changes in full-term infants during the first year of life. Vis Res. $2001 ; 41: 2799-810$.

20. Larsen JS. The sagittal growth of the eye: IV. Ultrasonic measurement of the axial length of the eye from birth to puberty. Acta Ophthalmol. 1971;49:873-86.

21. Larsen JS. The sagittal growth of the eye. 3. Ultrasonic measurement of the posterior segment (axial length of the vitreous) from birth to puberty. Acta Ophthalmol. 1971;49:441-53.

22. Sorsby A, Leary G, Richards MJ. Correlation ametropia and component ametropia. Vis Res. 1962;2:309-13.

23. Isenberg SJ, Del Signore M, Chen A, Wei J, Christenson PD. Corneal topography of neonates and infants. Arch Ophthalmol. 2004;122:1767-71.

24. Ehrlich DL, Braddick OJ, Atkinson J, et al. Infant emmetropization: longitudinal changes in refraction components from nine to twenty months of age. Optom Vis Sci. 1997;74:822-43.

25. Varughese S, Varghese RM, Gupta N, Ojha R, Sreenivas V, Puliyel JM. Refractive error at birth and its relation to gestational age. Curr Eye Res. 2005;30:423-8.

26. Friling R, Weinberger D, Kremer I, Avisar R, Sirota L, Snir M. Keratometry measurements in preterm and full term newborn infants. Br J Ophthalmol. 2004;88:8-10.

27. Rowland HC, Sayles N. Photokeratometric and photorefractive measurements of astigmatism in infants and young children. Vis Res. 1985;25:73-81.

28. Gwiazda J, Scheiman M, Mohindra I, Held R. Astigmatism in children: changes in axis and amount from birth to six years. Invest Ophthalmol Vis Sci. 1984;25:88-92.

29. Atkinson J, Braddick O, French J. Infant astigmatism: its disappearance with age. Vis Res. 1980;20:891-3.

30. Dobson V, Fulton A, Sebris SL. Cycloplegic refractions of infants and young children: the axis of astigmatism. Invest Ophthalmol Vis Sci. 1984;25:83-7.

31. Li SM, Iribarren R, Kang MT, et al. Corneal power, anterior segment length and lens power in 14-year-old Chinese children: the Anyang Childhood Eye Study. Sci Rep. 2016;6:20243.

32. Carney LG, Mainstone JC, Henderson BA. Corneal topography and myopia. A cross-sectional study. Invest Ophthalmol Vis Sci. 1997;38:311-20.

33. AlMahmoud T, Priest D, Munger R, Jackson WB. Correlation between refractive error, corneal power, and thickness in a large population with a wide range of ametropia. Invest Ophthalmol Vis Sci. 2011;52:1235-42.

34. Xie R, Zhou XT, Lu F, et al. Correlation between myopia and major biometric parameters of the eye: a retrospective clinical study. Optom Vis Sci. 2009;86:E503-8.

35. Zhang YY, Jiang WJ, Teng ZE, et al. Corneal curvature radius and associated factors in Chinese children: the Shandong Children Eye Study. PLoS One. 2015;10:e0117481.

36. Breslin KM, O'Donoghue L, Saunders KJ. A prospective study of spherical refractive error and ocular components among Northern Irish schoolchildren (the NICER study). Invest Ophthalmol Vis Sci. 2013;54:4843-50.

37. Saw SM, Chua WH, Gazzard G, Koh D, Tan DT, Stone RA. Eye growth changes in myopic children in Singapore. Br J Ophthalmol. 2005;89:1489-94.

38. Scheiman M, Gwiazda J, Zhang Q, et al. Longitudinal changes in corneal curvature and its relationship to axial length in the Correction of Myopia Evaluation Trial (COMET) cohort. J Opt. 2016;9:13-21.

39. Lin LL, Shih YF, Lee YC, Hung PT, Hou PK. Changes in ocular refraction and its components among medical studentsDOUBLEHYPHENa 5-year longitudinal study. Optom Vis Sci. 1996;73:495-8.

40. Ojaimi E, Rose KA, Morgan IG, et al. Distribution of ocular biometric parameters and refraction in a population-based study of Australian children. Invest Ophthalmol Vis Sci. 2005;46:2748-54. 
41. He X, Zou H, Lu L, et al. Axial length/corneal radius ratio: association with refractive state and role on myopia detection combined with visual acuity in Chinese schoolchildren. PLoS One. 2015;10:e111766.

42. Gonzalez Blanco F, Sanz Fernandez JC, Munoz Sanz MA. Axial length, corneal radius, and age of myopia onset. Optom Vis Sci. 2008;85:89-96.

43. Foo VH, Verkicharla PK, Ikram MK, et al. Axial length/corneal radius of curvature ratio and myopia in 3-year-old children. Transl Vis Sci Technol. 2016;5:5.

44. Ortiz S, Mena L, Rio-San Cristobal A, Martin R. Relationships between central and peripheral corneal thickness in different degrees of myopia. J Opt. 2014;7:44-50.

45. Pedersen L, Hjortdal J, Ehlers N. Central corneal thickness in high myopia. Acta Ophthalmol Scand. 2005;83:539-42.

46. Tong L, Saw SM, Siak JK, Gazzard G, Tan D. Corneal thickness determination and correlates in Singaporean schoolchildren. Invest Ophthalmol Vis Sci. 2004;45:4004-9.

47. Fam HB, How AC, Baskaran M, Lim KL, Chan YH, Aung T. Central corneal thickness and its relationship to myopia in Chinese adults. Br J Ophthalmol. 2006;90:1451-3.

48. Huang Y, Huang C, Li L, et al. Corneal biomechanics, refractive error, and axial length in Chinese primary school children. Invest Ophthalmol Vis Sci. 2011;52:4923-8.

49. Chang PY, Chang SW, Wang JY. Assessment of corneal biomechanical properties and intraocular pressure with the Ocular Response Analyzer in childhood myopia. Br J Ophthalmol. 2010;94:877-81.

50. Jiang Z, Shen M, Mao G, et al. Association between corneal biomechanical properties and myopia in Chinese subjects. Eye. 2011;25:1083-9.

51. Wang W, He M, He H, Zhang C, Jin H, Zhong X. Corneal biomechanical metrics of healthy Chinese adults using Corvis ST. Cont Lens Anterior Eye. 2017;40:97-103.

52. Shen M, Fan F, Xue A, Wang J, Zhou X, Lu F. Biomechanical properties of the cornea in high myopia. Vis Res. 2008;48:2167-71.

53. Shih YF, Chiang TH, Lin LL. Lens thickness changes among school children in Taiwan. Invest Ophthalmol Vis Sci. 2009;50:2637-44.

54. Wong HB, Machin D, Tan SB, Wong TY, Saw SM. Ocular component growth curves among Singaporean children with different refractive error status. Invest Ophthalmol Vis Sci. 2010;51:1341-7.

55. Jones LA, Mitchell GL, Mutti DO, Hayes JR, Moeschberger ML, Zadnik K. Comparison of ocular component growth curves among refractive error groups in children. Invest Ophthalmol Vis Sci. 2005;46:2317-27.

56. Mutti DO, Mitchell GL, Sinnott LT, et al. Corneal and crystalline lens dimensions before and after myopia onset. Optom Vis Sci. 2012;89:251-62.

57. Iribarren R, Morgan IG, Chan YH, Lin X, Saw SM. Changes in lens power in Singapore Chinese children during refractive development. Invest Ophthalmol Vis Sci. 2012;53:5124-30.

58. Dubbelman M, Van der Heijde GL. The shape of the aging human lens: curvature, equivalent refractive index and the lens paradox. Vis Res. 2001;41:1867-77.

59. Li SM, Li SY, Kang MT, et al. Distribution of ocular biometry in 7- and 14-year-old Chinese children. Optom Vis Sci. 2015;92:566-72.

60. Richter GM, Wang M, Jiang X, et al. Ocular determinants of refractive error and its age- and sexrelated variations in the Chinese American Eye Study. JAMA Ophthalmol. 2017;135:724-32.

61. Zadnik K, Mutti DO, Mitchell GL, Jones LA, Burr D, Moeschberger ML. Normal eye growth in emmetropic schoolchildren. Optom Vis Sci. 2004;81:819-28.

62. Gwiazda J, Hyman L, Hussein M, et al. A randomized clinical trial of progressive addition lenses versus single vision lenses on the progression of myopia in children. Invest Ophthalmol Vis Sci. 2003;44:1492-500.

63. Lau JK, Vincent SJ, Collins MJ, Cheung SW, Cho P. Ocular higher-order aberrations and axial eye growth in young Hong Kong children. Sci Rep. 2018;8:6726.

64. Huang J, Wen D, Wang Q, et al. Efficacy comparison of 16 interventions for myopia control in children: a network meta-analysis. Ophthalmology. 2016;123:697-708. 
65. Read SA, Collins MJ, Vincent SJ, Alonso-Caneiro D. Choroidal thickness in myopic and nonmyopic children assessed with enhanced depth imaging optical coherence tomography. Invest Ophthalmol Vis Sci. 2013;54:7578-86.

66. Xiong S, He X, Deng J, et al. Choroidal thickness in 3001 Chinese children aged 6 to 19 years using swept-source OCT. Sci Rep. 2017;7:45059.

67. Chen FK, Yeoh J, Rahman W, Patel PJ, Tufail A, Da Cruz L. Topographic variation and interocular symmetry of macular choroidal thickness using enhanced depth imaging optical coherence tomography. Invest Ophthalmol Vis Sci. 2012;53:975-85.

68. Esmaeelpour M, Povazay B, Hermann B, et al. Three-dimensional 1060-nm OCT: choroidal thickness maps in normal subjects and improved posterior segment visualization in cataract patients. Invest Ophthalmol Vis Sci. 2010;51:5260-6.

69. Gupta P, Jing T, Marziliano P, et al. Distribution and determinants of choroidal thickness and volume using automated segmentation software in a population-based study. Am J Ophthalmol. 2015;159:293-301.e293.

70. Li XQ, Munkholm A, Larsen M, Munch IC. Choroidal thickness in relation to birth parameters in 11- to 12-year-old children: the Copenhagen Child Cohort 2000 Eye Study. Invest Ophthalmol Vis Sci. 2014;56:617-24.

71. Ouyang Y, Heussen FM, Mokwa N, et al. Spatial distribution of posterior pole choroidal thickness by spectral domain optical coherence tomography. Invest Ophthalmol Vis Sci. 2011;52:7019-26.

72. Tan CS, Cheong KX. Macular choroidal thicknesses in healthy adultsDOUBLEHYPHENrelationship with ocular and demographic factors. Invest Ophthalmol Vis Sci. 2014;55:6452-8.

73. Wei WB, Xu L, Jonas JB, et al. Subfoveal choroidal thickness: the Beijing Eye Study. Ophthalmology. 2013;120:175-80.

74. Sanchez-Cano A, Orduna E, Segura F, et al. Choroidal thickness and volume in healthy young white adults and the relationships between them and axial length, ammetropy and sex. Am J Ophthalmol. 2014;158:574-83.

75. He X, Jin P, Zou H, et al. Choroidal thickness in healthy Chinese children aged 6 to 12: The Shanghai Children Eye Study. Retina. 2017;37:368-75.

76. Jin P, Zou H, Zhu J, et al. Choroidal and retinal thickness in children with different refractive status measured by swept-source optical coherence tomography. Am J Ophthalmol. 2016;168:164-76.

77. Zhang JM, Wu JF, Chen JH, et al. Macular choroidal thickness in children: the Shandong Children Eye Study. Invest Ophthalmol Vis Sci. 2015;56:7646-52.

78. Zhou LX, Shao L, Xu L, Wei WB, Wang YX, You QS. The relationship between scleral staphyloma and choroidal thinning in highly myopic eyes: the Beijing Eye Study. Sci Rep. 2017;7:9825.

79. Wang NK, Lai CC, Chou CL, et al. Choroidal thickness and biometric markers for the screening of lacquer cracks in patients with high myopia. PLoS One. 2013;8:e53660.

80. Ikuno Y, Jo Y, Hamasaki T, Tano Y. Ocular risk factors for choroidal neovascularization in pathologic myopia. Invest Ophthalmol Vis Sci. 2010;51:3721-5.

81. Nishida Y, Fujiwara T, Imamura Y, Lima LH, Kurosaka D, Spaide RF. Choroidal thickness and visual acuity in highly myopic eyes. Retina. 2012;32:1229-36.

82. Read SA, Alonso-Caneiro D, Vincent SJ, Collins MJ. Longitudinal changes in choroidal thickness and eye growth in childhood. Invest Ophthalmol Vis Sci. 2015;56:3103-12.

83. Fontaine M, Gaucher D, Sauer A, Speeg-Schatz C. Choroidal thickness and ametropia in children: a longitudinal study. Eur J Ophthalmol. 2017;27:730-4.

84. Jin $\mathrm{P}, \mathrm{Zou} \mathrm{H}, \mathrm{Xu} \mathrm{X}$, et al. Longitudinal changes in choroidal and retinal thicknesses in children with myopic shift. Retina. 2019;39:1091-9.

85. Chen Z, Xue F, Zhou J, Qu X, Zhou X. Effects of orthokeratology on choroidal thickness and axial length. Optom Vis Sci. 2016;93:1064-71.

86. Li Z, Cui D, Hu Y, Ao S, Zeng J, Yang X. Choroidal thickness and axial length changes in myopic children treated with orthokeratology. Cont Lens Anterior Eye. 2017;40:417-23. 
87. Sander BP, Collins MJ, Read SA. The effect of topical adrenergic and anticholinergic agents on the choroidal thickness of young healthy adults. Exp Eye Res. 2014;128:181-9.

88. Zhang Z, Zhou Y, Xie Z, et al. The effect of topical atropine on the choroidal thickness of healthy children. Sci Rep. 2016;6:34936.

89. Read SA. Ocular and environmental factors associated with eye growth in childhood. Optom Vis Sci. 2016;93:1031-41.

90. Elsheikh A, Geraghty B, Alhasso D, Knappett J, Campanelli M, Rama P. Regional variation in the biomechanical properties of the human sclera. Exp Eye Res. 2010;90:624-33.

91. Norman RE, Flanagan JG, Rausch SM, et al. Dimensions of the human sclera: thickness measurement and regional changes with axial length. Exp Eye Res. 2010;90:277-84.

92. Vurgese S, Panda-Jonas S, Jonas JB. Scleral thickness in human eyes. PLoS One. 2012;7:e29692.

93. McBrien NA, Gentle A. Role of the sclera in the development and pathological complications of myopia. Prog Retin Eye Res. 2003;22:307-38.

94. Downs JC, Ensor ME, Bellezza AJ, Thompson HW, Hart RT, Burgoyne CF. Posterior scleral thickness in perfusion-fixed normal and early-glaucoma monkey eyes. Invest Ophthalmol Vis Sci. 2001;42:3202-8.

95. Nemeth J. The posterior coats of the eye in glaucoma. An echobiometric study. Graefes Arch Clin Exp Ophthalmol. 1990;228:33-5.

96. Xue A, Bao F, Zheng L, Wang Q, Cheng L, Qu J. Posterior scleral reinforcement on progressive high myopic young patients. Optom Vis Sci. 2014;91:412-8.

97. Xue A, Zheng L, Tan G, et al. Genipin-crosslinked donor sclera for posterior scleral contraction/reinforcement to fight progressive myopia. Invest Ophthalmol Vis Sci. 2018;59:3564-73.

98. Read SA, Alonso-Caneiro D, Vincent SJ, et al. Anterior eye tissue morphology: scleral and conjunctival thickness in children and young adults. Sci Rep. 2016;6:33796.

99. Buckhurst HD, Gilmartin B, Cubbidge RP, Logan NS. Measurement of scleral thickness in humans using anterior segment optical coherent tomography. PLoS One. 2015;10:e0132902.

100. Pekel G, Yagci R, Acer S, Ongun GT, Cetin EN, Simavli H. Comparison of corneal layers and anterior sclera in emmetropic and myopic eyes. Cornea. 2015;34:786-90.

101. Consejo A, Radhakrishnan H, Iskander DR. Scleral changes with accommodation. Ophthalmic Physiol Opt. 2017;37:263-74.

102. Woodman-Pieterse EC, Read SA, Collins MJ, Alonso-Caneiro D. Anterior scleral thickness changes with accommodation in myopes and emmetropes. Exp Eye Res. 2018;177:96-103.

103. Bailey MD, Sinnott LT, Mutti DO. Ciliary body thickness and refractive error in children. Invest Ophthalmol Vis Sci. 2008;49:4353-60.

104. Kuchem MK, Sinnott LT, Kao CY, Bailey MD. Ciliary muscle thickness in anisometropia. Optom Vis Sci. 2013;90:1312-20.

105. Muftuoglu O, Hosal BM, Zilelioglu G. Ciliary body thickness in unilateral high axial myopia. Eye. 2009;23:1176-81.

106. Phillips JR, Khalaj M, McBrien NA. Induced myopia associated with increased scleral creep in chick and tree shrew eyes. Invest Ophthalmol Vis Sci. 2000;41:2028-34.

107. Siegwart JT Jr, Norton TT. Regulation of the mechanical properties of tree shrew sclera by the visual environment. Vis Res. 1999;39:387-407.

108. Sherman SM, Norton TT, Casagrande VA. Myopia in the lid-sutured tree shrew (Tupaia glis). Brain Res. 1977;124:154-7.

109. Wallman J, Turkel J, Trachtman J. Extreme myopia produced by modest change in early visual experience. Science. 1978;201:1249-51.

110. Wilson J, Sherman S. Differential effects of early monocular deprivation on binocular and monocular segments of cat striate cortex. J Neurophysiol. 1977;40:891-903.

111. Hodos W, Kuenzel WJ. Retinal-image degradation produces ocular enlargement in chicks. Invest Ophthalmol Vis Sci. 1984;25:652-9.

112. Wallman J, Ledoux C, Friedman MB. Simple devices for restricting the visual fields of birds. Behav Res Methods Instrum. 1978;10:401-3. 
113. Howlett MH, McFadden SA. Form-deprivation myopia in the guinea pig (Cavia porcellus). Vis Res. 2006;46:267-83.

114. Ashby R, Ohlendorf A, Schaeffel F. The effect of ambient illuminance on the development of deprivation myopia in chicks. Invest Ophthalmol Vis Sci. 2009;50:5348-54.

115. Schaeffel F, Howland HC. Properties of the feedback loops controlling eye growth and refractive state in the chicken. Vis Res. 1991;31:717-34.

116. Schmid KL, Wildsoe CF. Contrast and spatial-frequency requirements for emmetropization in chicks. Vis Res. 1997;37:2011-21.

117. Wiesel TN, Raviola E. Myopia and eye enlargement after neonatal lid fusion in monkeys. Nature. 1977;266(5597):66-8.

118. Wildsoet CF, Schmid KL. Optical correction of form deprivation myopia inhibits refractive recovery in chick eyes with intact or sectioned optic nerves. Vis Res. 2000;40:3273-82.

119. Siegwart JT Jr, Norton TT. The susceptible period for deprivation-induced myopia in tree shrew. Vis Res. 1998;38:3505-15.

120. Troilo D, Nickla DL. The response to visual form deprivation differs with age in marmosets. Invest Ophthalmol Vis Sci. 2005;46:1873-81.

121. Smith EL, Hung L-F, C-s K, Qiao Y. Effects of brief periods of unrestricted vision on the development of form-deprivation myopia in monkeys. Invest Ophthalmol Vis Sci. 2002;43:291-9.

122. Smith EL, Li-Fang H, Harwerth RS. Effects of optically induced blur on the refractive status of young monkeys. Vis Res. 1994;34:293-301.

123. Schaeffel F, Feldkaemper M. Animal models in myopia research. Clin Exp Optom. 2015;98:507-17.

124. McBrien NA, Lawlor P, Gentle A. Scleral remodeling during the development of and recovery from axial myopia in the tree shrew. Invest Ophthalmol Vis Sci. 2000;41:3713-9.

125. Troilo D, Nickla DL, Wildsoet CF. Choroidal thickness changes during altered eye growth and refractive state in a primate. Invest Ophthalmol Vis Sci. 2000;41:1249-58.

126. Gottlieb MD, Joshi HB, Nickla DL. Scleral changes in chicks with form-deprivation myopia. Curr Eye Res. 1990;9:1157-65.

127. Hung LF, Wallman J, Smith EL. Vision-dependent changes in the choroidal thickness of macaque monkeys. Invest Ophthalmol Vis Sci. 2000;41:1259-69.

128. Funata M, Tokoro T. Scleral change in experimentally myopic monkeys. Graefes Arch Clin Exp Ophthalmol. 1990;228:174-9.

129. Smith EL 3rd, Hung LF. Form-deprivation myopia in monkeys is a graded phenomenon. Vis Res. 2000;40:371-81.

130. Troilo D, Gottlieb MD, Wallman J. Visual deprivation causes myopia in chicks with optic nerve section. Curr Eye Res. 1987;6:993-9.

131. Norton TT, Rada JA. Reduced extracellular matrix in mammalian sclera with induced myopia. Vis Res. 1995;35:1271-81.

132. Gottlieb MD, Fugate-Wentzek LA, Wallman J. Different visual deprivations produce different ametropias and different eye shapes. Invest Ophthalmol Vis Sci. 1987;28:1225-35.

133. Troilo D, Li T, Glasser A, Howland HC. Differences in eye growth and the response to visual deprivation in different strains of chicken. Vis Res. 1995;35:1211-6.

134. McKanna JA, Casagrande VA. Reduced lens development in lid-suture myopia. Exp Eye Res. 1978;26:715-23.

135. Napper GA, Brennan NA, Barrington M, Squires MA, Vessey GA, Vingrys AJ. The duration of normal visual exposure necessary to prevent form deprivation myopia in chicks. Vis Res. 1995;35:1337-44.

136. O'Leary D, Millodot M. Eyelid closure causes myopia in humans. Experientia. 1979;35:1478-9.

137. von Noorden GK, Lewis RA. Ocular axial length in unilateral congenital cataracts and blepharoptosis. Invest Ophthalmol Vis Sci. 1987;28:750-2.

138. Gee SS, Tabbara KF. Increase in ocular axial length in patients with corneal opacification. Ophthalmology. 1988;95:1276-8.

139. Miller-Meeks MJ, Bennett SR, Keech RV, Blodi CF. Myopia induced by vitreous hemorrhage. Am J Ophthalmol. 1990;109:199-203. 
140. Bartmann M, Schaeffel F. A simple mechanism for emmetropization without cues from accommodation or colour. Vis Res. 1994;34:873-6.

141. Papastergiou GI, Schmid GF, Laties AM, Pendrak K, Lin T, Stone RA. Induction of axial eye elongation and myopic refractive shift in one-year-old chickens. Vis Res. 1998;38:1883-8.

142. Wildsoet C, Anchong R, Manasse J, Troilo D. Susceptibility to experimental myopia declines with age in the chick. Optom Vis Sci. 1998;75:265.

143. Bradley D, Fernandes A, Boothe R. Form deprivation myopia in adolescent monkeys. Optom Vis Sci. 1999;76:428-32.

144. Troilo D, Nickla DL, Wildsoet CF. Form deprivation myopia in mature common marmosets (Callithrix jacchus). Invest Ophthalmol Vis Sci. 2000;41:2043-9.

145. Schaeffel F, Glasser A, Howland HC. Accommodation, refractive error and eye growth in chickens. Vis Res. 1988;28:639-57.

146. Irving EL, Callender MG, Sivak JG. Inducing myopia, hyperopia, and astigmatism in chicks. Optom Vis Sci. 1991;68:364-8.

147. Irving EL, Sivak JG, Callender MG. Refractive plasticity of the developing chick eye. Ophthalmic Physiol Opt. 1992;12:448-56.

148. Schmid KL, Wildsoet CF. Effects on the compensatory responses to positive and negative lenses of intermittent lens wear and ciliary nerve section in chicks. Vis Res. 1996;36:1023-36.

149. Siegwart J, Norton T. Refractive and ocular changes in tree shrews raised with plus or minus lenses. Invest Ophthalmol Vis Sci. 1993;34:1208.

150. Hung LF, Crawford ML, Smith EL. Spectacle lenses alter eye growth and the refractive status of young monkeys. Nat Med. 1995;1:761-5.

151. Graham B, Judge SJ. The effects of spectacle wear in infancy on eye growth and refractive error in the marmoset (Callithrix jacchus). Vis Res. 1999;39:189-206.

152. Howlett MH, McFadden SA. Spectacle lens compensation in the pigmented guinea pig. Vis Res. 2009;49:219-27.

153. McFadden SA, Howlett MH, Mertz JR. Retinoic acid signals the direction of ocular elongation in the guinea pig eye. Vis Res. 2004;44:643-53.

154. Barathi VA, Boopathi VG, Yap EP, Beuerman RW. Two models of experimental myopia in the mouse. Vis Res. 2008;48:904-16.

155. Metlapally S, McBrien NA. The effect of positive lens defocus on ocular growth and emmetropization in the tree shrew. J Vis. 2008;8:1-12.

156. McFadden S, Wallman J. Guinea-pig eye growth compensates for spectacle lenses. Invest Ophthalmol Vis Sci. 1995;19106:S758.

157. Schaeffel F, Howland HC, Farkas L. Natural accommodation in the growing chicken. Vis Res. 1986;26:1977-93.

158. Whatham AR, Judge SJ. Compensatory changes in eye growth and refraction induced by daily wear of soft contact lenses in young marmosets. Vis Res. 2001;41:267-73.

159. Zhu X, Winawer JA, Wallman J. Potency of myopic defocus in spectacle lens compensation. Invest Ophthalmol Vis Sci. 2003;44:2818-27.

160. Chiang ST, Phillips JR, Backhouse S. Effect of retinal image defocus on the thickness of the human choroid. Ophthalmic Physiol Opt. 2015;35:405-13.

161. Read SA, Collins MJ, Sander BP. Human optical axial length and defocus. Invest Ophthalmol Vis Sci. 2010;51:6262-9.

162. Wang D, Chun RKM, Liu M, et al. Optical defocus rapidly changes choroidal thickness in school children. PLoS One. 2016;11:e161535.

163. Chakraborty R, Read SA, Collins MJ. Hyperopic defocus and diurnal changes in human choroid and axial length. Optom Vis Sci. 2013;90:1187-98.

164. Chakraborty R, Read SA, Collins MJ. Monocular myopic defocus and daily changes in axial length and choroidal thickness of human eyes. Exp Eye Res. 2012;103:47-54.

165. Moderiano D, Do M, Hobbs S, et al. Influence of the time of day on axial length and choroidal thickness changes to hyperopic and myopic defocus in human eyes. Exp Eye Res. 2019;182:125-36.

166. Zhu X, Wallman J. Temporal properties of compensation for positive and negative spectacle lenses in chicks. Invest Ophthalmol Vis Sci. 2009;50:37-46. 
167. Zhu X. Temporal integration of visual signals in lens compensation (a review). Exp Eye Res. 2013;114:69-76.

168. Winawer J, Wallman J. Temporal constraints on lens compensation in chicks. Vis Res. 2002;42:2651-68.

169. Zhu X, Park TW, Winawer J, Wallman J. In a matter of minutes, the eye can know which way to grow. Invest Ophthalmol Vis Sci. 2005;46:2238-41.

170. Wallman J, Adams JI. Developmental aspects of experimental myopia in chicks: susceptibility, recovery and relation to emmetropization. Vis Res. 1987;27:1139-63.

171. Norton TT. Experimental myopia in tree shrews. Ciba Found Symp. 1990;155:178-94.

172. Nickla DL, Wildsoet C, Wallman J. Visual influences on diurnal rhythms in ocular length and choroidal thickness in chick eyes. Exp Eye Res. 1998;66:163-81.

173. Troilo D, Wallman J. The regulation of eye growth and refractive state: an experimental study of emmetropization. Vis Res. 1991;31:1237-50.

174. Schaeffel F, Troilo D, Wallman J, Howland HC. Developing eyes that lack accommodation grow to compensate for imposed defocus. Vis Neurosci. 1990;4:177-83.

175. Schwahn HN, Schaeffel F. Chick eyes under cycloplegia compensate for spectacle lenses despite six-hydroxy dopamine treatment. Invest Ophthalmol Vis Sci. 1994;35:3516-24.

176. Chung KM. Critical review: effects of optical defocus on refractive development and ocular growth and relation to accommodation. Optom Vis Sci. 1993;70:228-33.

177. Morgan IG, Ashby RS, Nickla DL. Form deprivation and lens-induced myopia: are they different? Ophthalmic Physiol Opt. 2013;33:355-61.

178. C-S K, Marzani D, Wallman J. Differences in time course and visual requirements of ocular responses to lenses and diffusers. Invest Ophthalmol Vis Sci. 2001;42:575-83.

179. Bartmann M, Schaeffel F, Hagel G, Zrenner E. Constant light affects retinal dopamine levels and blocks deprivation myopia but not lens-induced refractive errors in chickens. Vis Neurosci. 1994;11:199-208.

180. Padmanabhan V, Shih J, Wildsoet CF. Constant light rearing disrupts compensation to imposed- but not induced-hyperopia and facilitates compensation to imposed myopia in chicks. Vis Res. 2007;47:1855-68.

181. Smith EL, Hung LF, Huang J. Protective effects of high ambient lighting on the development of form-deprivation myopia in rhesus monkeys. Invest Ophthalmol Vis Sci. 2012;53:421-8.

182. Ashby RS, Schaeffel F. The effect of bright light on lens compensation in chicks. Invest Ophthalmol Vis Sci. 2010;51:5247-53.

183. Feldkaemper M, Schaeffel F. An updated view on the role of dopamine in myopia. Exp Eye Res. 2013;114:106-19.

184. Dong F, Zhi Z, Pan M, et al. Inhibition of experimental myopia by a dopamine agonist: different effectiveness between form deprivation and hyperopic defocus in guinea pigs. Mol Vis. 2011;17:2824-34.

185. Harper AR, Summers JA. The dynamic sclera: extracellular matrix remodeling in normal ocular growth and myopia development. Exp Eye Res. 2015;133:100-11.

186. Crewther DP. The role of photoreceptors in the control of refractive state. Prog Retin Eye Res. 2000;19:421-57.

187. Wildsoet CF. Neural pathways subserving negative lens-induced emmetropization in chicks-insights from selective lesions of the optic nerve and ciliary nerve. Curr Eye Res. 2003;27:371-85.

188. Wallman J, Gottlieb MD, Rajaram V, Fugate-Wentzek LA. Local retinal regions control local eye growth and myopia. Science. 1987;237:73-7.

189. Diether S, Schaeffel F. Local changes in eye growth induced by imposed local refractive error despite active accommodation. Vis Res. 1997;37:659-68.

190. Smith EL, Huang J, Hung LF, Blasdel TL, Humbird TL, Bockhorst KH. Hemiretinal form deprivation: evidence for local control of eye growth and refractive development in infant monkeys. Invest Ophthalmol Vis Sci. 2009;50:5057-69.

191. Stone RA, Lin T, Laties AM, Iuvone PM. Retinal dopamine and form-deprivation myopia. Proc Natl Acad Sci U S A. 1989;86:704-6. 
192. Iuvone PM, Tigges M, Stone RA, Lambert S, Laties AM. Effects of apomorphine, a dopamine receptor agonist, on ocular refraction and axial elongation in a primate model of myopia. Invest Ophthalmol Vis Sci. 1991;32:1674-7.

193. Nickla DL, Wilken E, Lytle G, Yom S, Mertz J. Inhibiting the transient choroidal thickening response using the nitric oxide synthase inhibitor l-NAME prevents the ameliorative effects of visual experience on ocular growth in two different visual paradigms. Exp Eye Res. 2006;83:456-64.

194. Nickla DL, Wildsoet CF. The effect of the nonspecific nitric oxide synthase inhibitor NG-nitro-L-arginine methyl ester on the choroidal compensatory response to myopic defocus in chickens. Optom Vis Sci. 2004;81:111-8.

195. Feldkaemper MP, Schaeffel F. Evidence for a potential role of glucagon during eye growth regulation in chicks. Vis Neurosci. 2002;19:755-66.

196. Zhou X, Pardue MT, Iuvone PM, Qu J. Dopamine signaling and myopia development: what are the key challenges. Prog Retin Eye Res. 2017;61:60-71.

197. Pendrak K, Nguyen T, Lin T, Capehart C, Zhu X, Stone RA. Retinal dopamine in the recovery from experimental myopia. Curr Eye Res. 1997;16:152-7.

198. Iuvone PM, Tigges M, Fernandes A, Tigges J. Dopamine synthesis and metabolism in rhesus monkey retina: development, aging, and the effects of monocular visual deprivation. Vis Neurosci. 1989;2:465-71.

199. Crewther DP, Crewther SG, Xie RZ. Changes in eye growth produced by drugs which affect retinal ON or OFF responses to light. J Ocul Pharmacol Ther. 1996;12:193-208.

200. Crewther DP, Crewther SG. Pharmacological modification of eye growth in normally reared and visually deprived chicks. Curr Eye Res. 1990;9:733-40.

201. Chakraborty R, Park H, Aung MH, et al. Comparison of refractive development and retinal dopamine in OFF pathway mutant and C57BL/6J wild-type mice. Mol Vis. 2014;20:1318-27.

202. Chakraborty R, Pardue MT. Molecular and biochemical aspects of the retina on refraction. Prog Mol Biol Transl Sci. 2015;134:249-67.

203. Chakraborty R, Park HN, Hanif AM, Sidhu CS, Iuvone PM, Pardue MT. ON pathway mutations increase susceptibility to form-deprivation myopia. Exp Eye Res. 2015;137:79-83.

204. Bergen MA, Chakraborty R, Landis EG, Sidhu C, He L, Iuvone PM, Pardue MT. Altered refractive development in mice with reduced levels of retinal dopamine. Invest Ophthalmol Vis Sci. 2016;57(10):4412-9.

205. Pardue MT, Faulkner AE, Fernandes A, et al. High susceptibility to experimental myopia in a mouse model with a retinal on pathway defect. Invest Ophthalmol Vis Sci. 2008;49:706-12.

206. Markand S, Baskin NL, Chakraborty R, et al. IRBP deficiency permits precocious ocular development and myopia. Mol Vis. 2016;22:1291-308.

207. Zhang Q, Xiao X, Li S, et al. Mutations in NYX of individuals with high myopia, but without night blindness. Mol Vis. 2007;13:330-6.

208. Xu X, Li S, Xiao X, Wang P, Guo X, Zhang Q. Sequence variations of GRM6 in patients with high myopia. Mol Vis. 2009;15:2094-100.

209. Pras E, Abu A, Rotenstreich Y, et al. Cone-rod dystrophy and a frameshift mutation in the PROM1 gene. Mol Vis. 2009;15:1709.

210. Sieving PA, Fishman GA. Refractive errors of retinitis pigmentosa patients. Br J Ophthalmol. 1978;62:163-7.

211. Charman WN. Aberrations and myopia. Ophthalmic Physiol Opt. 2005;25:285-301.

212. Wildsoet CF, Atchison DA, Collins MJ. Longitudinal chromatic aberration as a function of refractive error. Clin Exp Optom. 1993;76:119-22.

213. Little JA, McCullough SJ, Breslin KM, Saunders KJ. Higher order ocular aberrations and their relation to refractive error and ocular biometry in children. Invest Ophthalmol Vis Sci. 2014;55:4791-800.

214. Buehren T, Collins MJ, Carney LG. Near work induced wavefront aberrations in myopia. Vis Res. 2005;45:1297-312.

215. Vincent SJ, Collins MJ, Read SA, Carney LG, Yap MK. Corneal changes following near work in myopic anisometropia. Ophthalmic Physiol Opt. 2013;33:15-25. 
216. Hiraoka T, Kotsuka J, Kakita T, Okamoto F, Oshika T. Relationship between higher-order wavefront aberrations and natural progression of myopia in schoolchildren. Sci Rep. 2017;7:7876.

217. Atchison DA, Li SM, Li H, et al. Relative peripheral hyperopia does not predict development and progression of myopia in children. Invest Ophthalmol Vis Sci. 2015;56:6162-70.

218. Lee TT, Cho P. Relative peripheral refraction in children: twelve-month changes in eyes with different ametropias. Ophthalmic Physiol Opt. 2013;33:283-93.

219. Cheng X, Xu J, Chehab K, Exford J, Brennan N. Soft contact lenses with positive spherical aberration for myopia control. Optom Vis Sci. 2016;93:353-66.

220. Hiraoka T, Okamoto C, Ishii Y, Kakita T, Oshika T. Contrast sensitivity function and ocular higher-order aberrations following overnight orthokeratology. Invest Ophthalmol Vis Sci. 2007:48:550-6.

221. Hiraoka T, Miyata K, Nakamura Y, et al. Influences of cycloplegia with topical atropine on ocular higher-order aberrations. Ophthalmology. 2013;120:8-13.

222. Huang HM, Chang DS, Wu PC. The association between near work activities and myopia in children-a systematic review and meta-analysis. PLoS One. 2015;10:e0140419.

223. Rosenfield M, Gilmartin B. Disparity-induced accommodation in late-onset myopia. Ophthalmic Physiol Opt. 1988;8:353-5.

224. Gwiazda J, Thorn F, Bauer J, Held R. Myopic children show insufficient accommodative response to blur. Invest Ophthalmol Vis Sci. 1993;34:690-4.

225. McBrien NA, Millodot M. The effect of refractive error on the accommodative response gradient. Ophthalmic Physiol Opt. 1986;6:145-9.

226. Gwiazda J, Bauer J, Thorn F, Held R. A dynamic relationship between myopia and blurdriven accommodation in school-aged children. Vis Res. 1995;35:1299-304.

227. Abbott ML, Schmid KL, Strang NC. Differences in the accommodation stimulus response curves of adult myopes and emmetropes. Ophthalmic Physiol Opt. 1998;18:13-20.

228. Cheng D, Schmid KL, Woo GC, Drobe B. Randomized trial of effect of bifocal and prismatic bifocal spectacles on myopic progression: two-year results. Arch Ophthalmol. 2010;128:12-9.

229. Berntsen DA, Barr CD, Mutti DO, Zadnik K. Peripheral defocus and myopia progression in myopic children randomly assigned to wear single vision and progressive addition lenses. Invest Ophthalmol Vis Sci. 2013;54:5761-70.

230. Mutti DO, Mitchell GL, Jones LA, et al. Accommodation, acuity, and their relationship to emmetropization in infants. Optom Vis Sci. 2009;86:666-76.

231. Weiss S, Schaeffel F. Diurnal growth rhythms in the chicken eye: relation to myopia development and retinal dopamine levels. J Comp Physiol A. 1993;172:263-70.

232. Chakraborty R, Read SA, Collins MJ. Diurnal variations in axial length, choroidal thickness, intraocular pressure, and ocular biometrics. Invest Ophthalmol Vis Sci. 2011;52:5121-9.

233. Brown JS, Flitcroft DI, Ying GS, et al. In vivo human choroidal thickness measurements: evidence for diurnal fluctuations. Invest Ophthalmol Vis Sci. 2009;50:5-12.

234. Stone RA, Quinn GE, Francis EL, et al. Diurnal axial length fluctuations in human eyes. Invest Ophthalmol Vis Sci. 2004;45:63-70.

235. Li T, Troilo D, Glasser A, Howland HC. Constant light produces severe corneal flattening and hyperopia in chickens. Vis Res. 1995;35:1203-9.

236. Guyton DL, Greene PR, Scholz RT. Dark-rearing interference with emmetropization in the rhesus monkey. Invest Ophthalmol Vis Sci. 1989;30:761-4.

237. Nickla DL, Totonelly K. Brief light exposure at night disrupts the circadian rhythms in eye growth and choroidal thickness in chicks. Exp Eye Res. 2016;146:189-95.

238. Nickla DL. The phase relationships between the diurnal rhythms in axial length and choroidal thickness and the association with ocular growth rate in chicks. J Comp Physiol A. 2006;192:399-407.

239. Kearney S, O’Donoghue L, Pourshahidi LK, Cobice D, Saunders KJ. Myopes have significantly higher serum melatonin concentrations than non-myopes. Ophthalmic Physiol Opt. 2017;37:557-67. 
240. Jee D, Morgan IG, Kim EC. Inverse relationship between sleep duration and myopia. Acta Ophthalmol. 2016;94:e204-10.

241. Mutti DO, Mitchell GL, Moeschberger ML, Jones LA, Zadnik K. Parental myopia, near work, school achievement, and children's refractive error. Invest Ophthalmol Vis Sci. 2002;43:3633-40.

242. Morgan IG. The biological basis of myopic refractive error. Clin Exp Optom. 2003;86:276-88.

243. Au Eong KG, Tay TH, Lim MK. Education and myopia in 110,236 young Singaporean males. Singap Med J. 1993;34:489-92.

244. Williams KM, Bertelsen G, Cumberland P, et al. Increasing prevalence of myopia in Europe and the impact of education. Ophthalmology. 2015;122:1489-97.

245. Mirshahi A, Ponto KA, Hoehn R, et al. Myopia and level of education: results from the Gutenberg Health Study. Ophthalmology. 2014;121:2047-52.

246. Read SA, Collins MJ, Woodman EC, Cheong SH. Axial length changes during accommodation in myopes and emmetropes. Optom Vis Sci. 2010;87:656-62.

247. Woodman-Pieterse EC, Read SA, Collins MJ, Alonso-Caneiro D. Regional changes in choroidal thickness associated with accommodation. Invest Ophthalmol Vis Sci. 2015;56:6414-22.

248. Hepsen IF, Evereklioglu C, Bayramlar H. The effect of reading and near-work on the development of myopia in emmetropic boys: a prospective, controlled, three-year follow-up study. Vis Res. 2001;41:2511-20.

249. Jones LA, Sinnott LT, Mutti DO, Mitchell GL, Moeschberger ML, Zadnik K. Parental history of myopia, sports and outdoor activities, and future myopia. Invest Ophthalmol Vis Sci. 2007;48:3524-32.

250. He M, Zheng Y, Xiang F. Prevalence of myopia in urban and rural children in mainland China. Optom Vis Sci. 2009;86:40-4.

251. He M, Huang W, Zheng Y, Huang L, Ellwein LB. Refractive error and visual impairment in school children in rural southern China. Ophthalmology. 2007;114:374-82.

252. Zhang M, Li L, Chen L, et al. Population density and refractive error among Chinese children. Invest Ophthalmol Vis Sci. 2010;51:4969-76.

253. Ip JM, Rose KA, Morgan IG, Burlutsky G, Mitchell P. Myopia and the urban environment: findings in a sample of 12-year-old Australian school children. Invest Ophthalmol Vis Sci. 2008;49:3858-63.

254. Choi KY, Yu WY, Lam CHI, et al. Childhood exposure to constricted living space: a possible environmental threat for myopia development. Ophthalmic Physiol Opt. 2017;37:568-75.

255. Parssinen O, Lyyra AL. Myopia and myopic progression among schoolchildren: a three-year follow-up study. Invest Ophthalmol Vis Sci. 1993;34:2794-802.

256. Rose KA, Morgan IG, Ip J, et al. Outdoor activity reduces the prevalence of myopia in children. Ophthalmology. 2008;115:1279-85.

257. Guo Y, Liu LJ, Tang P, et al. Outdoor activity and myopia progression in 4-year followup of Chinese primary school children: The Beijing Children Eye Study. PLoS One. 2017;12:e175921.

258. Guggenheim JA, Northstone K, McMahon G, et al. Time outdoors and physical activity as predictors of incident myopia in childhood: a prospective cohort study. Invest Ophthalmol Vis Sci. 2012;53:2856-65.

259. Parssinen O, Kauppinen M, Viljanen A. The progression of myopia from its onset at age 8-12 to adulthood and the influence of heredity and external factors on myopic progression. A 23-year follow-up study. Acta Ophthalmol. 2014;92:730-9.

260. Jones-Jordan LA, Sinnott LT, Cotter SA, et al. Time outdoors, visual activity, and myopia progression in juvenile-onset myopes. Invest Ophthalmol Vis Sci. 2012;53:7169-75.

261. Sherwin JC, Reacher MH, Keogh RH, Khawaja AP, Mackey DA, Foster PJ. The association between time spent outdoors and myopia in children and adolescents: a systematic review and meta-analysis. Ophthalmology. 2012;119:2141-51.

262. Flitcroft DI. The complex interactions of retinal, optical and environmental factors in myopia aetiology. Prog Retin Eye Res. 2012;31:622-60.

263. Cohen Y, Belkin M, Yehezkel O, Solomon AS, Polat U. Dependency between light intensity and refractive development under light-dark cycles. Exp Eye Res. 2011;92:40-6. 
264. Karouta C, Ashby RS. Correlation between light levels and the development of deprivation myopia. Invest Ophthalmol Vis Sci. 2014;56:299-309.

265. Smith EL, Hung LF, Arumugam B, Huang J. Negative lens-induced myopia in infant monkeys: effects of high ambient lighting. Invest Ophthalmol Vis Sci. 2013;54:2959-69.

266. Read SA, Collins MJ, Vincent SJ. Light exposure and eye growth in childhood. Invest Ophthalmol Vis Sci. 2015;56:6779-87.

267. Ostrin LA, Sajjadi A, Benoit JS. Objectively measured light exposure during school and summer in children. Optom Vis Sci. 2018;95:332-42.

268. Wu PC, Chen CT, Lin KK, et al. Myopia prevention and outdoor light intensity in a schoolbased cluster randomized trial. Ophthalmology. 2018;125(8):1239-50.

269. Rudnicka AR, Kapetanakis VV, Wathern AK, et al. Global variations and time trends in the prevalence of childhood myopia, a systematic review and quantitative meta-analysis: implications for aetiology and early prevention. Br J Ophthalmol. 2016;100:882-90.

270. French AN, Morgan IG, Burlutsky G, Mitchell P, Rose KA. Prevalence and 5- to 6-year incidence and progression of myopia and hyperopia in Australian school children. Ophthalmology. 2013;120:1482-91.

271. Read SA, Vincent SJ, Tan CS, Ngo C, Collins MJ, Saw SM. Patterns of daily outdoor light exposure in Australian and Singaporean children. Transl Vis Sci Technol. 2018;7:8.

272. Lan W, Feldkaemper M, Schaeffel F. Intermittent episodes of bright light suppress myopia in the chicken more than continuous bright light. PLoS One. 2014;9:e110906.

273. He M, Xiang F, Zeng Y, et al. Effect of time spent outdoors at school on the development of myopia among children in China: a randomized clinical trial. JAMA. 2015;314:1142-8.

274. Wu PC, Tsai CL, Wu HL, Yang YH, Kuo HK. Outdoor activity during class recess reduces myopia onset and progression in school children. Ophthalmology. 2013;120:1080-5.

275. Torii H, Kurihara T, Seko Y, et al. Violet light exposure can be a preventive strategy against myopia progression. EBioMedicine. 2017;15:210-9.

276. Foulds WS, Barathi VA, Luu CD. Progressive myopia or hyperopia can be induced in chicks and reversed by manipulation of the chromaticity of ambient light. Invest Ophthalmol Vis Sci. 2013;54:8004-12.

277. Smith EL, Hung LF, Arumugam B, Holden BA, Neitz M, Neitz J. Effects of long-wavelength lighting on refractive development in infant rhesus monkeys. Invest Ophthalmol Vis Sci. 2015;56:6490-500.

278. Gawne TJ, Ward AH, Norton TT. Long-wavelength (red) light produces hyperopia in juvenile and adolescent tree shrews. Vis Res. 2017;140:55-65.

279. Jiang L, Zhang S, Schaeffel F, et al. Interactions of chromatic and lens-induced defocus during visual control of eye growth in guinea pigs (Cavia porcellus). Vis Res. 2014;94:24-32.

Open Access This chapter is licensed under the terms of the Creative Commons Attribution 4.0 International License (http://creativecommons.org/licenses/by/4.0/), which permits use, sharing, adaptation, distribution and reproduction in any medium or format, as long as you give appropriate credit to the original author(s) and the source, provide a link to the Creative Commons license and indicate if changes were made.

The images or other third party material in this chapter are included in the chapter's Creative Commons license, unless indicated otherwise in a credit line to the material. If material is not included in the chapter's Creative Commons license and your intended use is not permitted by statutory regulation or exceeds the permitted use, you will need to obtain permission directly from the copyright holder. 